Two-way slabs: Experimental investigation

of load redistributions in steel fibre reinforced concrete

David Fall, Jiangpeng Shu, Rasmus Rempling, Karin Lundgren and Kamyab Zandi

Published in Engineering Structures,

http://www.journals.elsevier.com/engineering-structures

full reference:

Fall, D., Jiangpeng, S., Rempling, R., Lundgren, K. and Zandi, K. (2014): Two-way slabs:

Experimental investigation of load redistributions in steel fibre reinforced concrete,

Engineering Structures 80 (2014) pp. 61-74, http://dx.doi.org/10.1016/j.engstruct.2014.08.033. 


\title{
Two-Way Slabs: Experimental Investigation of Load Redistributions in Steel Fibre Reinforced Concrete
}

\author{
David Fall ${ }^{\mathrm{a}, *}$, Jiangpeng Shu ${ }^{\mathrm{a}}$, Rasmus Rempling ${ }^{\mathrm{a}}$, Karin Lundgren ${ }^{\mathrm{a}}$, Kamyab Zandi ${ }^{\mathrm{a}, \mathrm{b}}$ \\ ${ }^{a}$ Department of Civil and Environmental Engineering, Division of Structural Engineering, \\ Chalmers University of Technology, \\ Sven Hultins gata 8, 412 96 Gothenburg, Sweden \\ ${ }^{b}$ CBI Swedish Cement and Concrete Research Institute, Material Group, 50115 Borås, Sweden
}

\begin{abstract}
In the design of two-way reinforced concrete slabs, e.g. using the strip or yield line design method, the possibility of redistributing the load between different loading directions is used. The main aim of the present study was to investigate how fibres affect the structural behaviour such as the possibility for redistribution, crack patterns and load-carrying capacity. The investigation was conducted by means of experiments on two-way octagonal slabs, simply supported on four edges, centrically loaded with a point load. The slabs spanned $2.2 \mathrm{~m}$ in both directions and the reinforcement amount was twice as large in one direction as in the other, in order to provoke uneven load distribution. Three slabs of each reinforcement configuration were produced and tested: conventionally reinforced slabs, steel fibre reinforced slabs and a combination of both reinforcement types. The reaction force on each supported edge was measured on five rollers per edge. A moderate fibre content $\left(35 \mathrm{~kg} / \mathrm{m}^{3}\right)$ of double hook-end steel fibres was used. The steel fibres affected the structural behaviour significantly by providing post-cracking ductility and by increasing the ultimate load-carrying capacity by approximately 20\%. Most significant, the steel fibres influenced the load redistribution in such a way that more load could be transferred to supports in the weaker direction after cracking. Further, more evenly distributed support reactions were obtained in the slabs containing both reinforcement types compared to the case when only conventional reinforcement was used. The slabs reinforced by steel fibres alone did not experience any bending hardening; however, a considerable post-cracking ductility was observed. Furthermore, the work presented in this paper will provide results suitable for use in benchmarking numerical and analytical modelling methods for steel fibre reinforced concrete, as the experimental programme also included extensive testing of material properties.
\end{abstract}

Keywords: Concrete slab, steel fiber reinforced concrete, experimental investigation, load distribution

${ }^{*}$ Corresponding author. Tel.: +4631 772 2248; fax: +4631 7722260

Email address: david.fall@chalmers.se (David Fall) 


\section{Introduction}

Although the use of steel fibre reinforced concrete (SFRC) has been increasing over the past two decades, the anticipated implementation of SFRC may have been hindered by a lack of guidelines and knowledge concerning the influence on structural behaviour, e.g. plastic redistribution. Extensive research has proved that steel fibres provide significant post-crack ductility to the otherwise brittle concrete. This effect has been quantified in numerous studies [1, 2, 3] and standards have been developed for assessing characteristic material parameters, e.g. fracture energy [4, 5]. A common application of SFRC is in industrial flooring, i.e. slabs on ground [6, 7]. More recently, SFRC has also been used as the only type of reinforcement in elevated slabs [8] or in combination with conventional reinforcement [9]. Documented benefits of SFRC include both the bending [6, 10] and shear capacity [1] of slabs. In the design of two-way reinforced concrete slabs, e.g. using the strip or yield line design method, the possibility of redistributing the load between different load-carrying directions is commonly used.

Plastic redistribution fundamentally affects the structural design of concrete structures; a characteristic that incorporates the statical indeterminacy in the design of reinforced concrete, e.g. using the strip method [12] or yield line theory [13]. However, experiments designed to quantify the influence of steel fibres on the load redistribution, have to the knowledge of the authors not been performed before, although some effects have been observed [14].

In this study, the effects of steel fibres on bi-directional load redistribution have been quantified through experiments. In addition to the distribution between the two loadcarrying directions, the load distribution over the length of the support was also measured. Furthermore, as the experimental programme also included extensive testing of material properties, the work presented in this paper will provide results suitable for use in benchmarking numerical and analytical modelling methods for steel fibre reinforced concrete.

To study redistribution, a structure that would to a high degree illustrate such an effect was chosen: a two-way slab unsymmetrically reinforced by conventional reinforcement. The geometry and test set-up were chosen in order to induce a flexural failure. To study redistribution, the distribution of reaction forces during loading was monitored. To facilitate this study, a support system using hollow steel rollers with strain gauges was developed. A finite element analysis was used prior to experiments to verify both the global structural behaviour and the local behaviour of the support rollers. The design of the test set-up is discussed further in Section 2

\section{Design of Test Set-up}

\subsection{Review of experimental work in the literature}

Previous experimental work on the influence of steel fibres in reinforced concrete slabs has, as mentioned, resulted in benefits, e.g. increased punching shear resistance and increased flexural ductility. A number of studies have been conducted on the influence of steel fibre reinforcement on the punching behaviour of two-way slabs, concluding that steel 
fibres increase punching shear resistance [15, 16, 11]. Generally, slab-column specimens have been used.

Furthermore, an increase in both capacity and ductility of wall panels has been reported. Ganesan et al. [17] present a study on the effect of $0.5 \%$ steel fibres on the strength and behaviour of reinforced concrete wall panels simply supported on all four edges. The panels were subjected to a uniformly distributed normal load applied with a minor eccentricity to simulate a typical load-bearing wall. Wall panel sizes ranged from 480x320 mm up to $1200 \times 800 \mathrm{~mm}$ (all with a thickness of $40 \mathrm{~mm}$ ). Extensive information on similar test set-ups can be found in e.g. Doh [18], who tested similar wall panels using conventional concrete.

Barros and Figueiras [2] conducted experiments on one-way slab strips in bending. The main purpose of the experiments was to verify an analytical model developed for steel fibre reinforced cross-sections. The strips had the dimension of $1.8 \times 0.5 \times 0.075 \mathrm{~m}$ and were reinforced both with conventional reinforcement and varying content of steel fibres $\left(0,30,45\right.$, and $\left.60 \mathrm{~kg} / \mathrm{m}^{3}\right)$. All slabs featuring steel fibre reinforcement showed some degree of bending hardening. Both ultimate capacity and ductility increased with higher fibre content.

Slabs of larger geometries have been tested in two-way bending in different test set-ups, with results depending on the amount of steel fibres added and the varying composition of conventional steel reinforcement. Døssland [8] presented tests performed on a full scale slab measuring $3 \times 7 \times 0.15 \mathrm{~m}$. About $0.8 \%$ steel fibres were used together with a minimum of conventional reinforcement bars resulting in higher capacities than expected. In addition, a slab with steel fibres as only flexural reinforcement, measuring 3.0x3.4x0.15 m, was tested. The slabs were loaded with a centric point load up until right before the expected failure. Due to joint reinforcement to the supporting walls, all four edges were considered fixed. Døssland [8] concluded that for shorter spans, SFRC can be used as sole reinforcement type. In Michels et al. [10], experiments on octagonal slabs (span 1.9-2.34 m, thickness 200-400 $\mathrm{mm})$ were presented. All the slabs were reinforced with steel fibres alone $\left(V_{\mathrm{f}}=1.3 \%(100\right.$ $\mathrm{kg} / \mathrm{m}^{3}$ ), undulated fibres) and failed in bending. The failure can be described as ductile, but without any significant bending hardening. The slabs were tested by being supported on a column positioned at the centre as well as by eight hydraulic jacks symmetrically placed along the free edges. Along with other experiments, Blanco [19] tested steel fibre reinforced concrete slabs. These slabs were $3 \mathrm{~m}$ long and $200 \mathrm{~mm}$ thick and the width varied between 1.5, 2.0 and $3.0 \mathrm{~m}$. Hooked end fibres were added to the concrete mix (40 $\mathrm{kg} / \mathrm{m}^{3}$ ) and no conventional reinforcement was used. The slabs were supported on four edges and failed in bending, without any bending hardening. Pujadas et al. [20] tested slabs, ranging up to $3 \times 3 \mathrm{~m}$, reinforced with polymeric fibres alone $\left(9 \mathrm{~kg} / \mathrm{m}^{3}\right)$. The $200 \mathrm{~mm}$ slabs were simply supported along the edges and tested in bending, evidencing a ductile behaviour. The supports were constituted by a trestle with a layer of neoprene panel.

Even though all experimental programmes mentioned provided important information on the behaviour of steel fibre reinforced concrete, none of the test set-ups was suitable for direct application facing the challenge at hand, i.e. investigating the influence of steel fibre on the load distribution. The test set-up used by Nguyen-Minh et al. [11], in which the 
load was centrically applied could be used given that the supporting edges were equipped for monitoring the reaction force. None of the two-way bending tests described monitored the load distribution. The test set-up used by Michels et al. [10] might possibly be used to study a given load distribution by prescribing an uneven application of load at the eight different loading points.

To conclude, a two-way bending test was necessary to gain a clear asymmetry in terms of one strong and one weak direction without biasing the load distribution with asymmetric load application. Furthermore, shear punching failure needed to be avoided, even in the case of conventional reinforcement alone. The development of the test set-up used in this study is further elaborated on in the following sections.

\subsection{Test set-up evolution}

Using concrete structures of complex shapes as a starting point, testing a shell-like structure with unsymmetrical conventional reinforcement would have been a potential option. Testing of such a complex structure would be associated with several challenges, e.g. an even load application, reproducibility and issues of handling. Alternatively, the shell might be represented only by the middle portion of a cross-like structure with unsymmetrical reinforcement (Figure $1 \mathrm{a}$ ). This structure would provide clear load redistributions, that were easy to measure because of the relatively short support length. However, due to a short yield line running diagonally from the centre to the corners of the centre portion, the failure would most likely occur already at a minor load. An opposite approach would be to test a square slab (Figure 1 $1 \mathrm{~b}$ ). This option would be preferable in several ways by providing better and more straight forward theoretical models and easier casting. The reaction forces would, however, be more difficult to measure along the entire support length and the crack pattern would likely be diffuse in the corner regions. To avoid these disadvantages, the corner regions were excluded, resulting in an octagonal slab (Figure 11;). Because of the limited numbers of load cells, the monitoring of reaction forces was done utilizing compressible steel pipes equipped with strain gauges (Section 3.1). The slab geometry and the amount of reinforcement bars were designed using the yield line method as presented in Section 2.3. Furthermore, the design was verified by a three-dimensional finite element model and the shear punching resistance was checked in accordance with Eurocode EN-1992-1-1 [21].

\subsection{Analytical estimation}

As mentioned, the expected failure load was estimated using the yield line method [13]. This well-recognised plastic analysis method relies on the choice of failure mechanism and is an upper bound approach; hence, there might be a more efficient failure mechanism forming at a lower load than the one calculated. Using yield line analysis in experimental work, the assumed failure mechanism can be verified against the actual failure mode, assuming that the crack pattern conforms to the yield lines.

The external work $(E W)$ by the concentrated load $P$, giving the virtual displacement $\delta$, is

$$
\sum E W=P \delta
$$




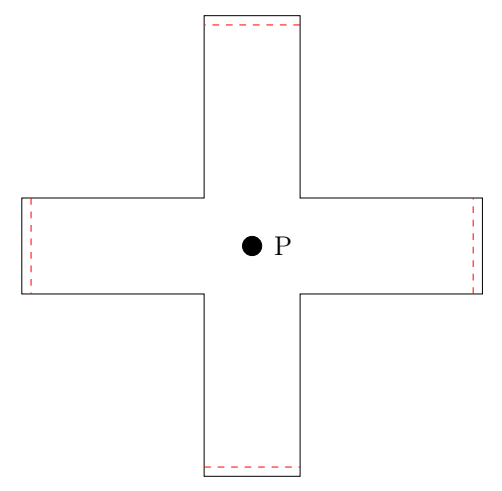

(a) Cross slab

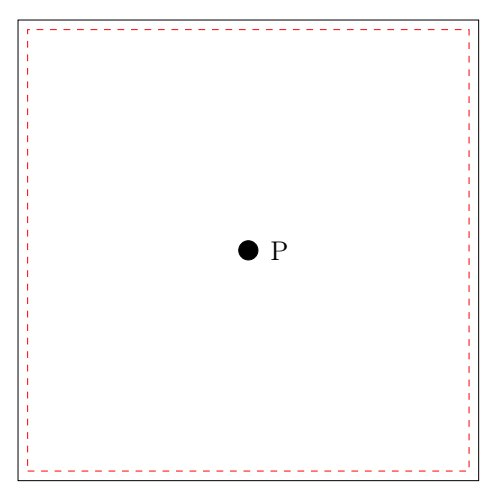

(b) Square slab

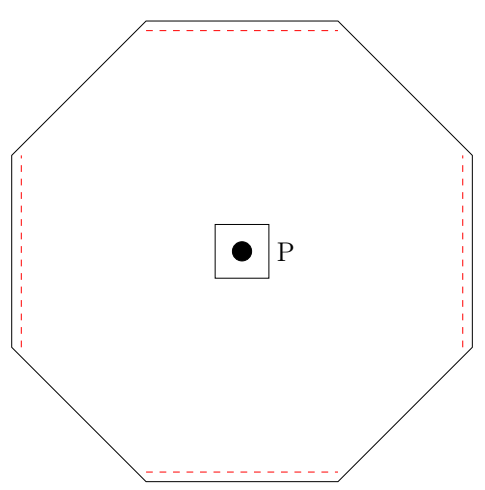

(c) Octagonal slab

Figure 1: Evolution of slab geometry set-up. Simply supported at dashed lines.

The total moment resisted by the reinforcement is, by considering moment equilibrium over a small element of the slab, calculated as

$$
m_{\mathrm{b}}=m_{\mathrm{x}} \sin ^{2}(\alpha)+m_{\mathrm{y}} \cos ^{2}(\alpha),
$$

where $\alpha$ is the angle at which the orthogonal reinforcement intersects the yield line [22]. The in-plane moment resisted in the $\mathrm{x}$ - and $\mathrm{y}$-direction, respectively, can simplified be calculated as:

$$
m_{\mathrm{x}}=d_{\mathrm{x}} A_{\mathrm{sx}} f_{\mathrm{y}} \text { and } m_{\mathrm{y}}=d_{\mathrm{y}} A_{\mathrm{sy}} f_{\mathrm{y}},
$$

assuming that the height of the compression zone is small. The internal work $(I W)$ is given by the moment resisted over the length of the yield line. The internal work is formulated by the moment resisted, the yield line length $\left(L_{Y}\right)$ and the rotation angle of the plastic mechanism. The rotation angle, $\theta$ is determined as:

$$
\theta=\frac{\delta}{L_{\mathrm{S}}}
$$

by assuming that the angle is minor and $L_{\mathrm{S}}$ is half the length of the diagonal of a square slab (Figure 2). The internal work is

$$
\sum I W=4 m_{\mathrm{b}} L_{\mathrm{Y}} 2 \theta=4 m_{\mathrm{b}} L_{\mathrm{Y}} 2 \frac{\delta}{L_{\mathrm{S}}}=8 m_{\mathrm{b}} \frac{L_{\mathrm{Y}}}{L_{\mathrm{S}}} \delta,
$$

By energy balance, Equations 1 and 5 are equal; hence, the ultimate point load becomes

$$
P=8 m_{\mathrm{b}} \frac{L_{\mathrm{Y}}}{L_{\mathrm{S}}} .
$$

Assuming the mechanism in Figure 2, the failure load (using conventionally reinforced concrete alone) was calculated as $P=40.5 \mathrm{kN}$. 


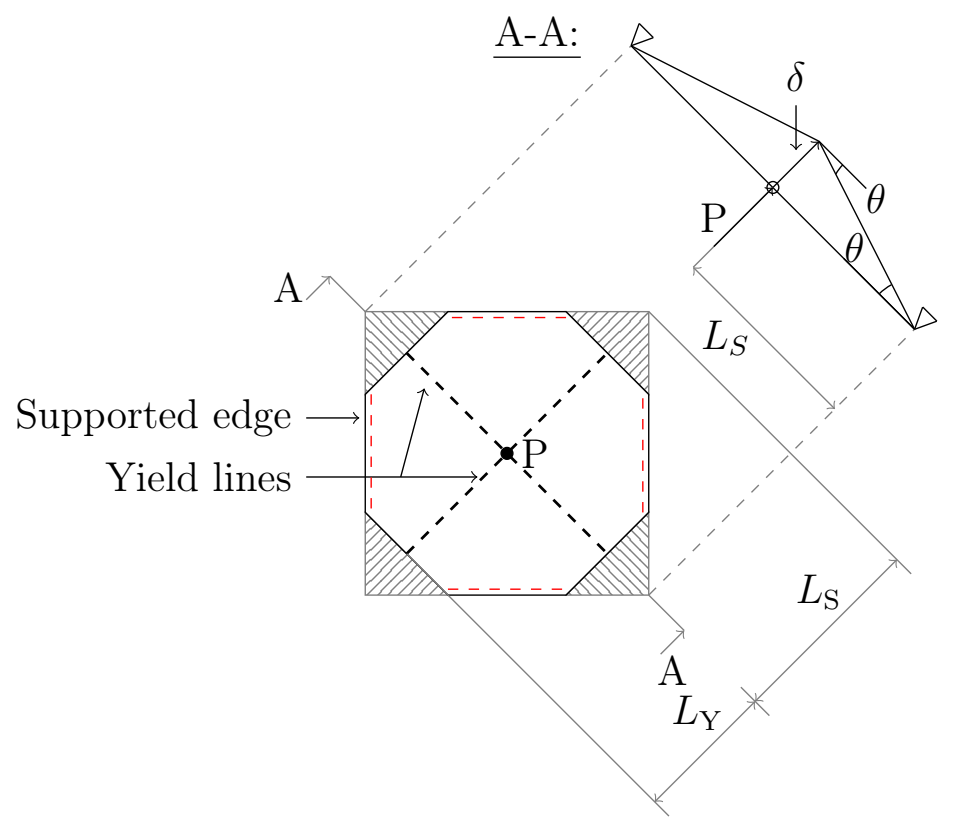

Figure 2: Assumed failure mode.

\subsection{Finite element analysis of support rollers}

As further described in Section 3.1, the strain gauges were glued to the sides of the supporting steel pipes. The dimensions of the steel pipe were chosen in order for the strains to be measurable without exceeding the yield strain (Figure 3). It was anticipated that when the slab was subjected to large deflections, the rollers would be rotated. In this case, the strain gauges would not be located on the spot of maximum strain. Therefore, it was necessary to assess the effect of such a rotation by considering the strain variation along the pipe circumference within a certain angle, $\alpha$. A finite element analysis of the pipe, using plane strain elements, was carried out to study the strain at the pipe surface (Figure 4). The results showed that when the roller was rotated, the measured strain would be lower than the maximum strain (Figure 5). According to the analysis performed, the error is negligible at angles smaller than approximately $5^{\circ}$. Using trigonometry, this angle limitation corresponds to a mid-span deformation of $96 \mathrm{~mm}$.

\section{Experiments}

\subsection{Test set-up}

The $2.4 \mathrm{~m}$ wide octagonal slabs were supported by 20 high-tolerance steel pipes (Steel quality S355, see Figure 3) and loaded with a point load in the center (Figure 6). A detail of the support is presented in Figure 7. Two strain gauges were glued to each pipe using a cyanoacrylate adhesive. Prior to testing of the slabs, each support roller was calibrated for the load range expected during the test. Each roller was tested during three loading cycles 

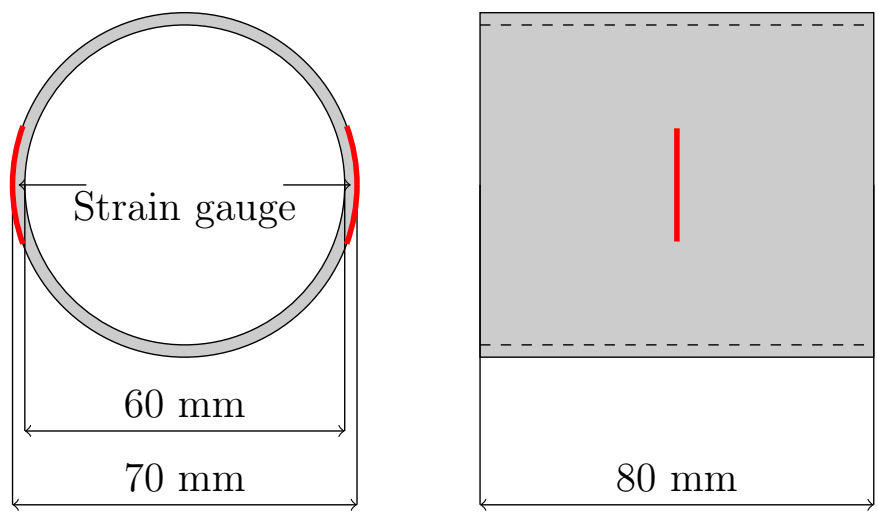

Figure 3: Support pipe.

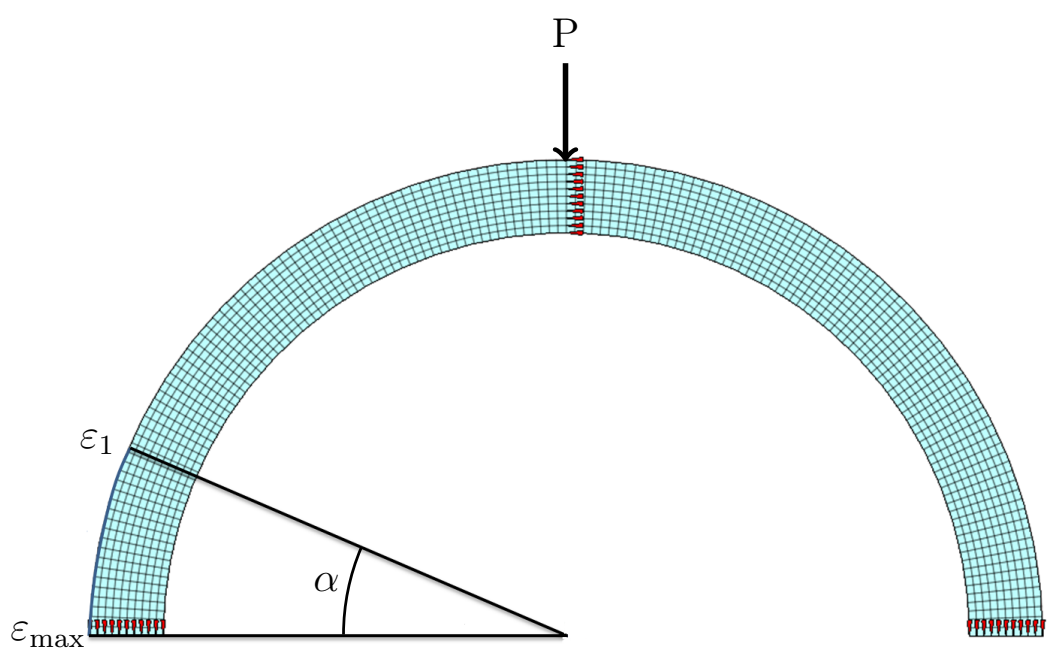

Figure 4: Plane strain model of steel support pipe.

and the average value of the linear load-strain relation was used to calculate the reaction forces presented in this study. The rollers were placed on a steel plate of high tolerance. The plate was bolted to a stiff substructure consisting of a square hollow section (VKR 150x150/6.3) bolted to a stiff support.

A loading jack was applied to a load cell $(500 \mathrm{kN})$ resting on a steel plate $(280 \times 280 x 30$ $\mathrm{mm})$. Additionally, a wood fibre board $(\mathrm{t}=12 \mathrm{~mm})$ was placed under the loading plate to ensure an even load distribution.

\subsection{Test series}

The test series comprised of nine slabs reinforced by conventional reinforcement and/or steel fibre reinforcement (Table 11). The layout of the conventional reinforcement is presented in Figure 8. As an extension to the study presented here, five textile reinforced 


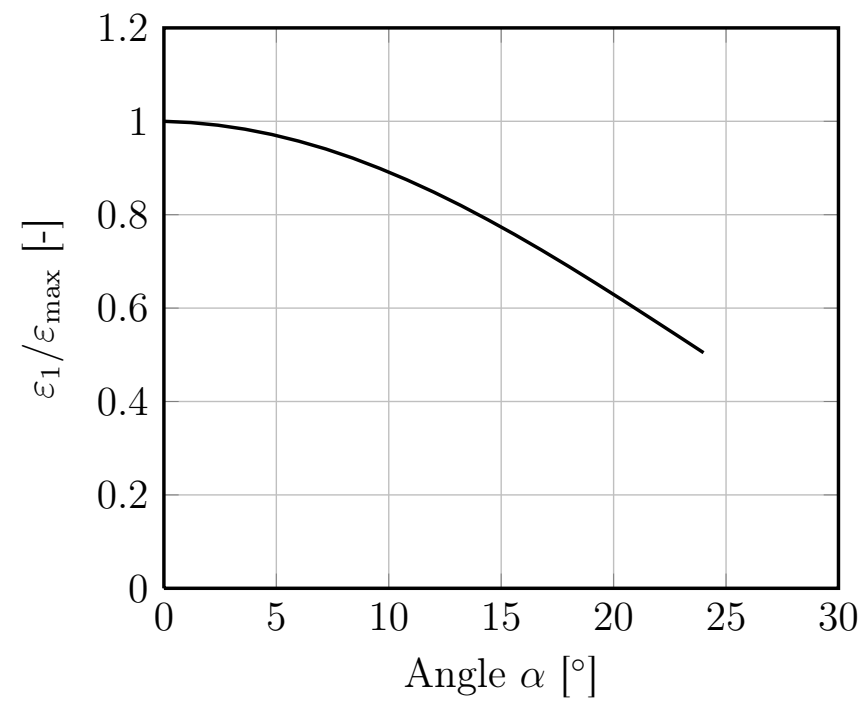

Figure 5: Principal strain variation along the circumference of the steel pipe.

concrete slabs were tested in the same fashion, see Williams Portal [23].

Table 1: Slab configurations. CR denotes slab with conventional reinforcement bars as only reinforcement type. CFR denote slabs with both conventional reinforcement bars and steel fibre reinforcement. Type FR are slabs with steel fibre reinforcement alone.

\begin{tabular}{|c|c|c|c|c|c|c|}
\hline \multirow[t]{2}{*}{ Type } & \multirow[t]{2}{*}{ \# } & \multirow[t]{2}{*}{$\begin{array}{l}\text { Reinforcement bars } \\
\text { (B500C) }\end{array}$} & \multirow[t]{2}{*}{$\begin{array}{l}\text { Steel fibres } \\
\text { (Dramix 5D) }\end{array}$} & \multicolumn{3}{|c|}{$\begin{array}{l}\text { Average measured thickness } \\
\text { of each slab }\end{array}$} \\
\hline & & & & 1 & 2 & 3 \\
\hline $\mathrm{CR}$ & 3 & $\phi 6$ (s194/96 & & $85.2 \mathrm{~mm}$ & $83.0 \mathrm{~mm}$ & $83.5 \mathrm{~mm}$ \\
\hline CFR & 3 & $\phi 6$ (s194/96 & $35 \mathrm{k}$ & $88.2 \mathrm{l}$ & $81.2 \mathrm{~mm}$ & $82.1 \mathrm{~mm}$ \\
\hline FR & 3 & - & $35 \mathrm{~kg} / \mathrm{m}^{3}$ & $78.1 \mathrm{~mm}$ & $79.4 \mathrm{~mm}$ & $79.7 \mathrm{~mm}$ \\
\hline
\end{tabular}

\subsection{Production of specimens}

Concrete used in all slabs came from two batches: one equipped with steel fibres and another without. The used steel fibre type had double end-hooks (DRAMIX 5D, L=60 $\mathrm{mm}$ and $\mathrm{d}=0.9 \mathrm{~mm}$ giving the aspect ratio $0.65(\mathrm{~L} / \mathrm{d}))$. Both mix compositions are shown in Table 2. The material properties are further described in Section 3.4 .

The self-compacting concrete was delivered from a ready-mix plant and all casting was made in the Structural Engineering Laboratory at the Chalmers University of Technology. All slabs and specimens for material tests were cast in one day. During the casting, the concrete was cast from a mixing truck chute and placed in the slab formwork in an S-shape. Prior to testing, the thickness of the slabs was measured at 95 evenly distributed points on 


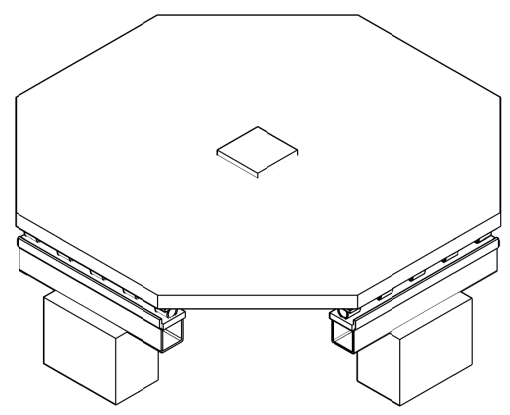

(a) Model

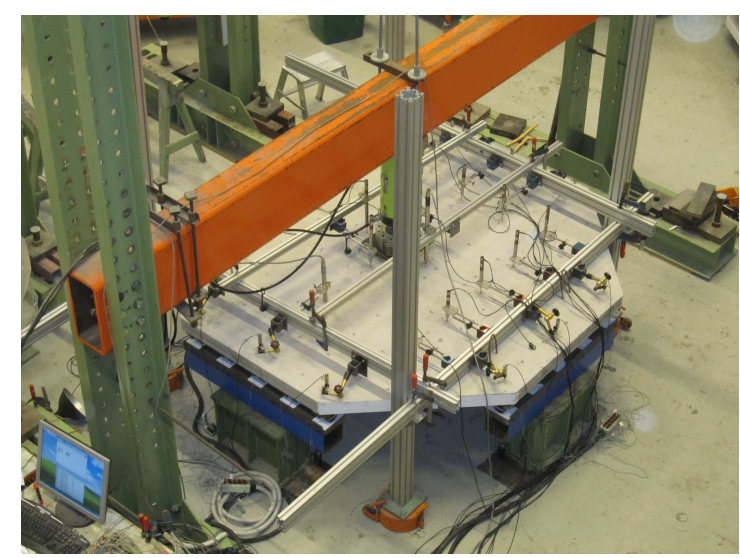

(b) Overview of the instrumented slab

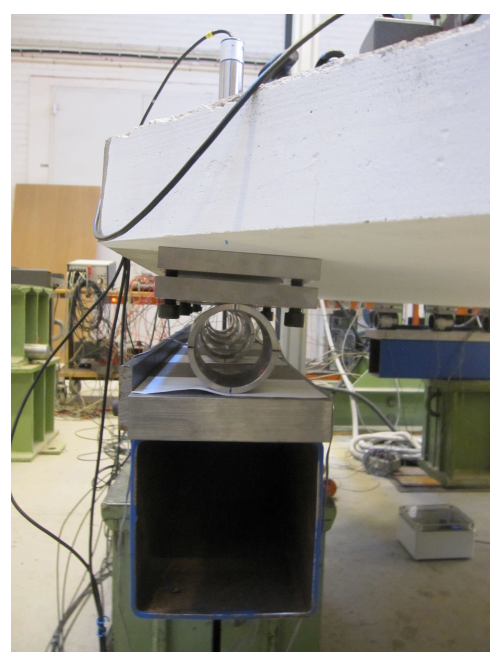

(c) Support section

Figure 6: Test set-up.

each slab. The average thicknesses are given in Table 1. The relatively thin slabs deserves to be commented: Researchers have shown that the tensile residual strength, and thereby the positive influence from steel fibre, decreases with increased thickness due to an increased three-dimensional distribution [10, 24]. Additionally, Svec [25] and Laranjeira et al. [26] showed that the fibre orientation in self-compacting concrete is highly dependent on the flow direction and tends towards a two-dimensional distribution. In the slabs studied, this has probably improved the structural performance of the fibre reinforced concrete. 

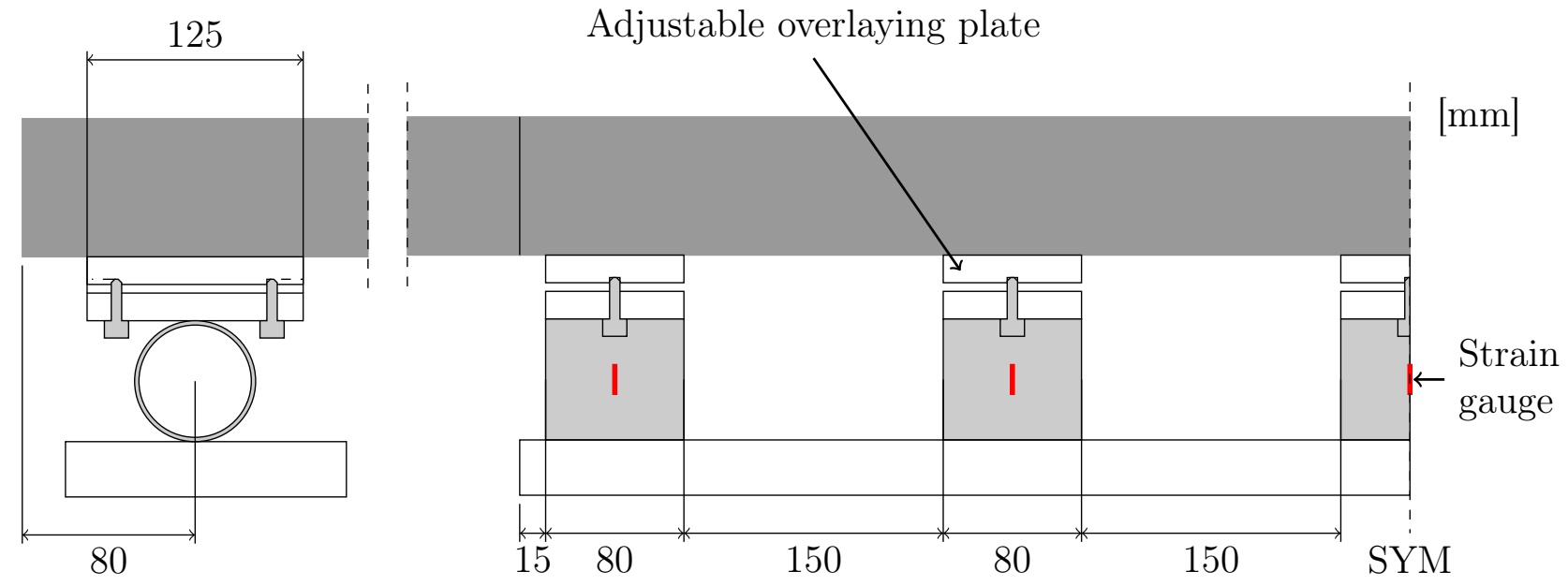

Figure 7: Detail of support.

\subsection{Material properties}

The compressive strength of the concrete was assessed through the testing of nine specimens from each concrete type; five cored cylinders $(\mathrm{d}=100 \mathrm{~mm}, \mathrm{~h}=200 \mathrm{~mm}$, tested according to EN12504-1 [27]), and four cubes (150x150x150 mm, tested accoding to EN12390-3 [28]). All specimens were stored in water until testing. Two cubes of each concrete type were tested 28 days after casting. Additionally two cubes from each batch were tested after the completion of the experimental programme (148 days after casting). Two cylinders were tested right before the testing of each slab type (plain concrete: 85 days, steel fibre reinforced concrete: 124 days) and additional three after the slab testing concluded (plain concrete: 124 days, steel fibre reinforced concrete: 154 days). The average cylinder strength was calculated (Table 22). Calculating the average strength, two tests of the plain concrete were left out due to technical problems, as well as the test conducted after 28 days. Furthermore, as only a minor strength increase was observed between 85 and 154 days the average values were calculated without any correction for specimen age. During the compressive testing, the modulus of elasticity was also assessed using extensometers after three loading cycles of $0.35 f_{\text {ck }}$.

Both uni-axial tension tests [5] and three-point bending tests [4 were performed to characterise the tensile behaviour of concrete. Results for both concrete types from the uniaxial tension tests, performed on notched cylinders, are shown in Figure 9. Six specimens of each concrete type were tested in uni-axial tension. A sudden stress drop occurs in three of the specimens, coinciding with the development of a second crack outside of the notch, leading to energy dissipating also in the new crack. The load at the limit of proportionality, the corresponding deflections and energy absorption capacities were calculated from the six three-point bending tests (3PBT) performed (Table 3). A considerable scatter could be observed, analysing the results from both test methods. It is further discussed in Rempling 


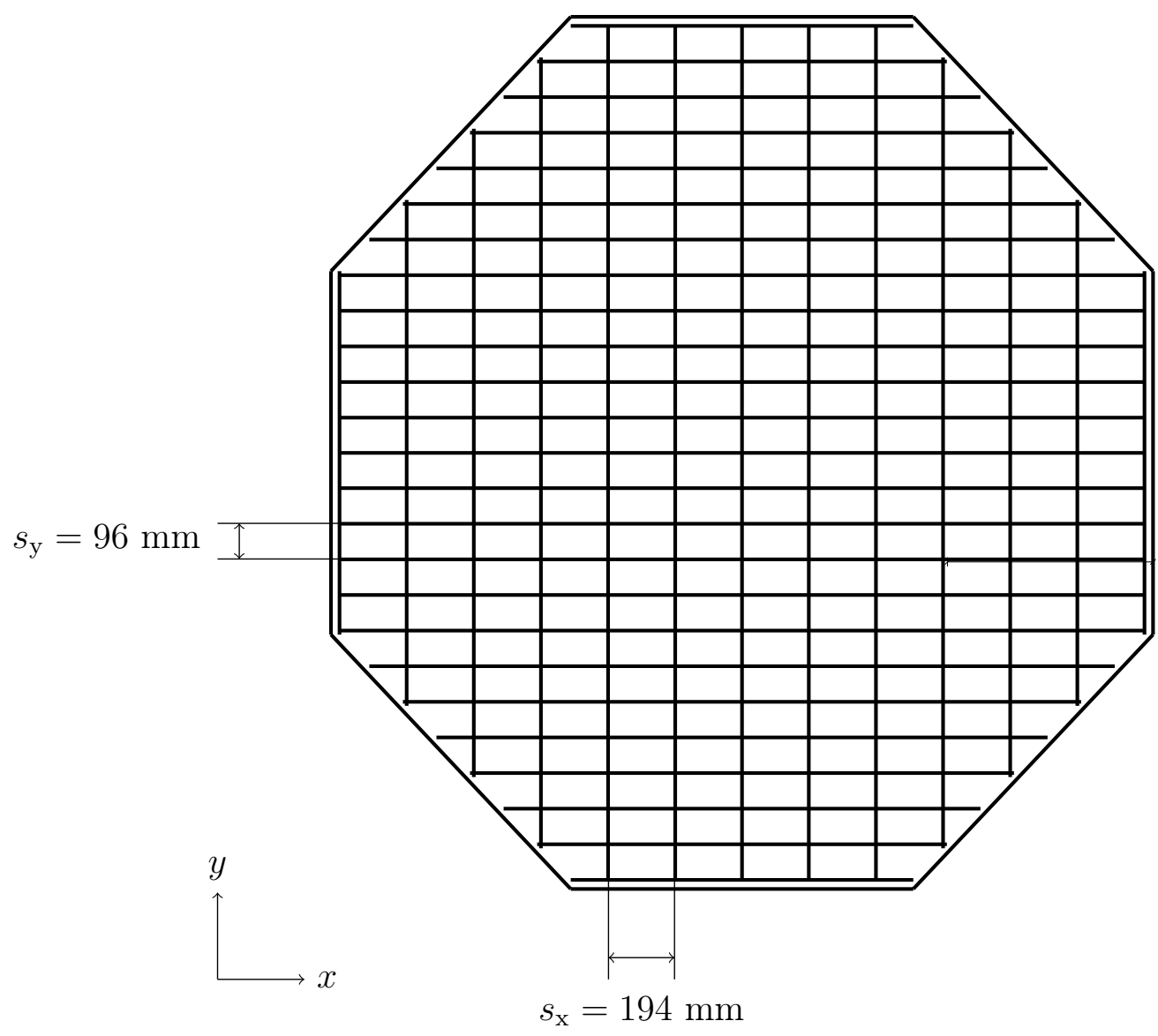

Figure 8: Conventional reinforcement layout.

et al. [29], were it is concluded that the scatter is related to the number of fibres bridging the fractured areas. Reinforcement bars were tested in tension and featured an average yield strength and ultimate strength of $550 \mathrm{MPa}$ and $666 \mathrm{MPa}$, respectively.

\subsection{Instrumentation}

In addition to the 40 strain gauges that were glued to the support rollers, 28 linear variable differential transformers (LVDTs) were used to measure the deformation on the top surface relative to the floor (Figure 10). Twelve LVDTs were placed over the supports, four surrounding the loading plate in the centre of the slab and twelve in an intermediate position between the loading and support positions. As seen in Figure 10, the intermediate LVDTs were more densely placed along one line in each direction. The logging frequency for all measurements was $1 \mathrm{~Hz}$.

\subsection{Test procedure}

Initially, the slab was placed on four temporary supports (one on each line of support rollers). The rollers were then positioned by adjustable overlaying plates in a vertical di- 
Table 2: Concrete mix compositions and properties.

\begin{tabular}{llcc} 
Constituents $\left[\mathrm{kg} / \mathrm{m}^{3}\right]$ & $\begin{array}{c}\text { Plain } \\
\text { concrete }\end{array}$ & $\begin{array}{c}\text { Fibre reinforced } \\
\text { concrete }\end{array}$ \\
\hline Cement & CEM II/A-LL 42,5R & 338 & 322 \\
Limestone filler & Limus 40 & 180 & 178 \\
\hline Sand & $0 / 4$ & 911 & 891 \\
Stone & $4 / 8$ (crushed) & 103 & 123 \\
Stone & $8 / 16$ (crushed) & 616 & 621 \\
\hline Superplasticizer & Glenium 51/18 (BASF) & $6.39(2 \%)$ & $6.41(2 \%)$ \\
Air entraining agent & MicroAir100 1:10 (BASF) & $0.47(0.15 \%)$ & $0.48(0.15 \%)$ \\
Fibre & Dramix 5D & - & 35 \\
\hline Free water & & 182.6 & 172.9 \\
\hline \hline Property & & & \\
\hline$f_{\text {c,mean }}[\mathrm{MPa}]$ & & $50.90 \pm 0.93$ & $44.29 \pm 1.52$ \\
$E_{\mathrm{c}}[\mathrm{GPa}]$ & & 31.73 & 30.93 \\
$f_{\text {ct,mean }}[\mathrm{MPa}]$ & & 2.70 & 2.99 \\
Slump flow [mm] & & 530 & 600
\end{tabular}

rection (Figure 7). These plates were positioned while controlling the strain measurements on the pipes to ensure that all supports were in contact with the slab at the start of the test. The temporary supports were removed before loading.

Loading was applied by means of deformation control; LVDT number LW25 was used to control the hydraulic jack (Figure 10). The initial loading speed was $0.25 \mathrm{~mm} / \mathrm{min}$. In the tests of the slabs including conventional reinforcement (CR and CFR), the loading speed was increased to $2.0 \mathrm{~mm} / \mathrm{min}$ after the initial crack formation and stiffness stabilisation (at a deformation of approximately $8 \mathrm{~mm}$ ). During the testing of slabs with steel fibres alone (FR), the speed was increased to $0.50 \mathrm{~mm} / \mathrm{min}$ when a stable post-crack behaviour was reached. 


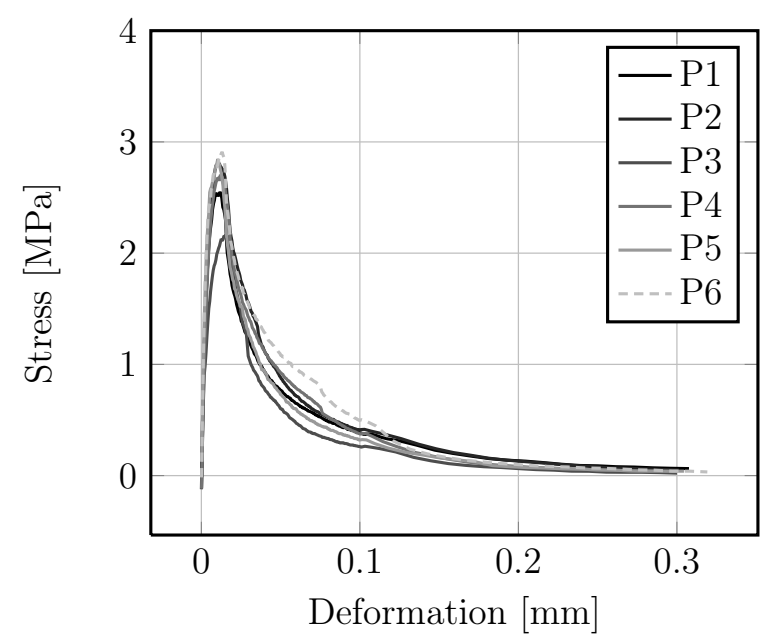

(a) Plain concrete

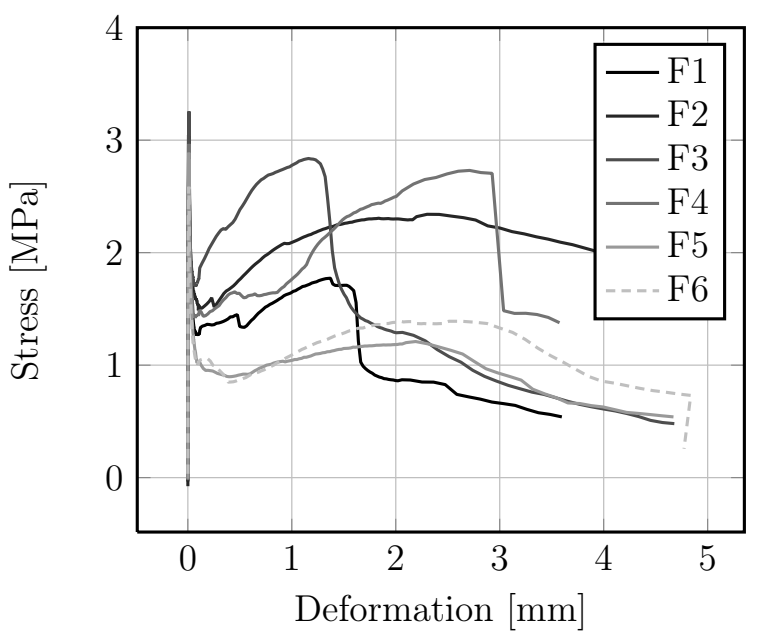

(b) Steel fibre reinforced concrete

Figure 9: Tensile properties from uni-axial tension tests. P1-P6 and F1-F6 is the sample labels for plain and fibre reinforced concrete, respectively.

Table 3: Results from the three-point bending tests. The capacities were calculated according to the recommendation in RILEM TC 162-TDF [4].

\begin{tabular}{c|cccccc} 
Spec. No. & $F_{\mathrm{L}}{ }^{a}[\mathrm{kN}]$ & $\delta_{\mathrm{L}}^{b}[\mathrm{~mm}]$ & $\begin{array}{c}\delta_{2}{ }^{c}[\mathrm{~mm}] \\
\delta_{\mathrm{L}}+0.650\end{array}$ & $\begin{array}{c}\left.\delta_{3}\right]^{d}[\mathrm{~mm}] \\
\delta_{\mathrm{L}}+2.650\end{array}$ & $D_{\mathrm{BZ}}{ }^{e}[\mathrm{kN} \mathrm{mm}]$ & $\left.D_{\mathrm{BZZ}}\right]^{f}[\mathrm{kN} \mathrm{mm}]$ \\
\hline 3PBT-1 & 13.0 & 0.048 & 0.698 & 2.698 & 2.91 & 17.88 \\
3PBT-2 & 14.0 & 0.043 & 0.693 & 2.693 & - & 5.15 \\
3PBT-3 & 13.0 & 0.045 & 0.695 & 2.695 & 2.16 & 10.69 \\
3PBT-4 & 14.1 & 0.078 & 0.728 & 2.728 & 5.16 & 32.16 \\
3PBT-5 & 14.0 & 0.046 & 0.696 & 2.696 & 4.59 & 28.47 \\
3PBT-6 & 15.5 & 0.049 & 0.699 & 2.699 & 6.97 & 34.40 \\
Average & & & & & 4.36 & 21.46
\end{tabular}

${ }^{a} F_{\mathrm{L}}$ - Load at limit of proportionality

${ }^{b}$ delt $a_{\mathrm{L}}$ - Displacement at limit of proportionality

${ }^{c} \delta_{2}$ - Deflection at $\mathrm{CMOD}_{2}$

${ }^{d} \delta_{3}$ - Deflection at $\mathrm{CMOD}_{3}$

${ }^{e} D_{\mathrm{BZ} 2}$ - Energy absorption capacity corresponding to $\mathrm{CMOD}_{2}$

${ }^{f} D_{\mathrm{BZ} 3}$ - Energy absorption capacity corresponding to $\mathrm{CMOD}_{3}$ 


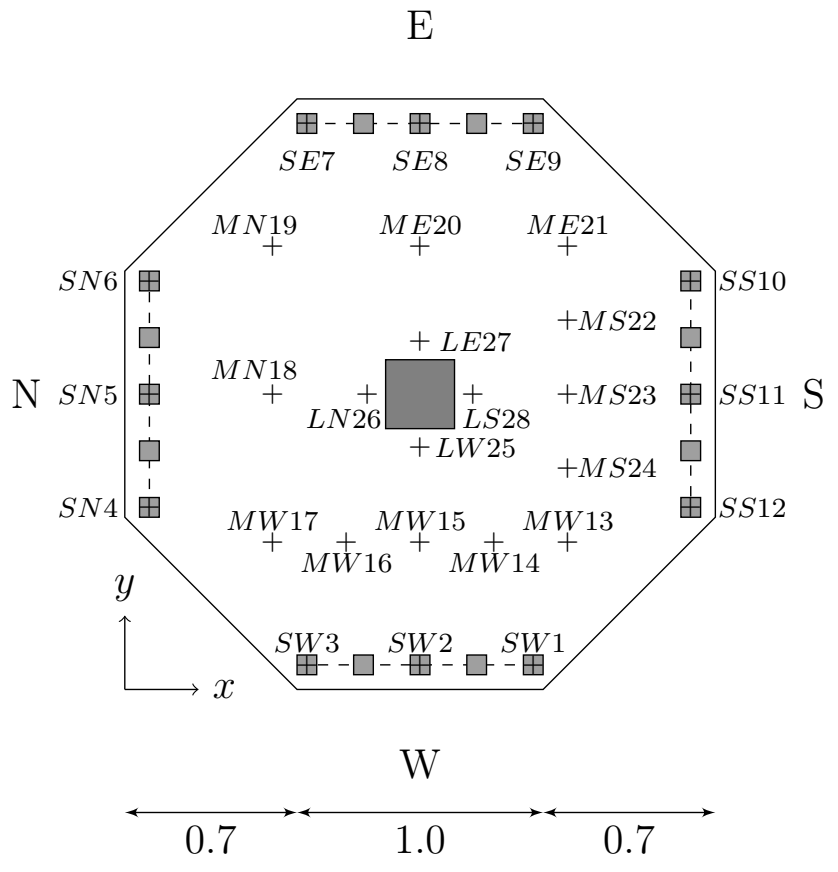

Figure 10: LVDT instrumentation. Deformation speed was controlled by LVDT LW25 located close to the loading plate. 


\section{Results}

\subsection{Load-deflection}

Results from all nine slab tests are summarised in Figure 11, where the load displacement graph is presented. All slabs with conventional reinforcement (CR) showed similar behaviour; elastic until cracking at $25-30 \mathrm{kN}$ followed by a clear bending hardening behaviour. The slabs with combined reinforcement (CFR) acted similarly, except that they exhibited higher stiffness during the cracked hardening stage. A considerably higher capacity was obtained by one of the slabs with combined reinforcement (CFR1) most likely due to the unintended larger thickness of this slab, observed and documented (Table 11). The slabs reinforced with steel fibres alone (FR) showed no bending hardening, i.e. the cracking load was the highest load applied during these tests. For the geometry and reinforcement content studied, it is notable that the residual capacity of the FR slabs roughly corresponded to the addition of ultimate capacity seen while comparing the results from $\mathrm{CR}$ and CFR slabs.

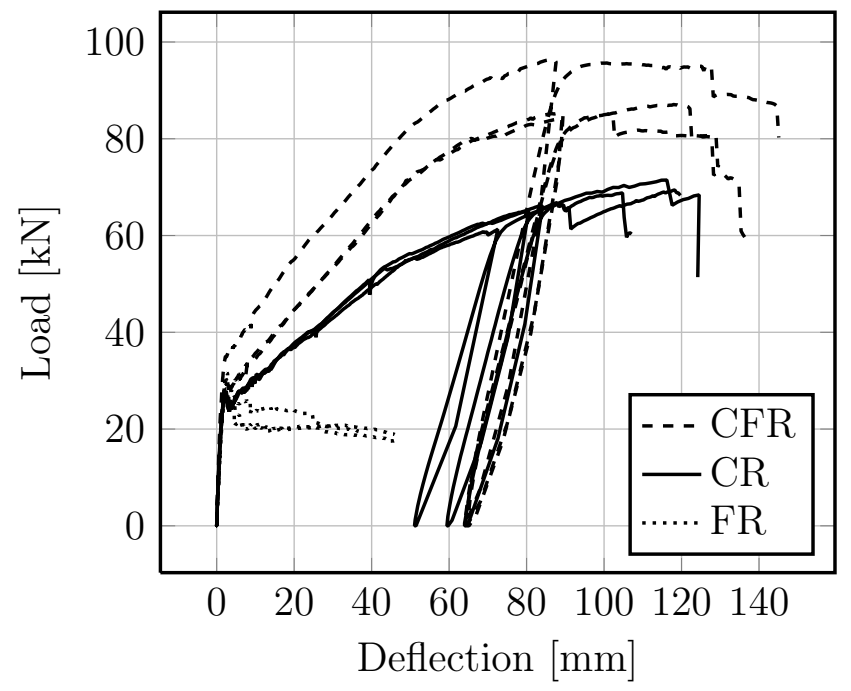

Figure 11: Load versus deflection (LVDT LW25), for all tested slabs.

The tests including conventional reinforcement were aborted at the rupture of the second reinforcement bar. While testing the slabs with steel fibre reinforcement alone, the tests were aborted when the diagonal bending crack was observed on the surface of the compressed side as well. The loading and unloading at a deformation of 50 to $80 \mathrm{~mm}$ were conducted due to range limitation in the load controlling LVDT; the test had to be stopped in order for the LVDT to be adjusted for further deformation.

As can be seen in Figure 10, deflections were also monitored in several intermediate positions. Measurements from the densely instrument lines formed by LVDTs 13-17 and LVDTs 13, 24, 23, 22 and 21 are presented for two slabs in Figures 12 and 13 . Considering these results, as well as the remainder of the series tested, no general trend emerged; 
the distributions of deformation in the two directions were equivalent. Furthermore, no significant difference was observed comparing the CR and CFR series.
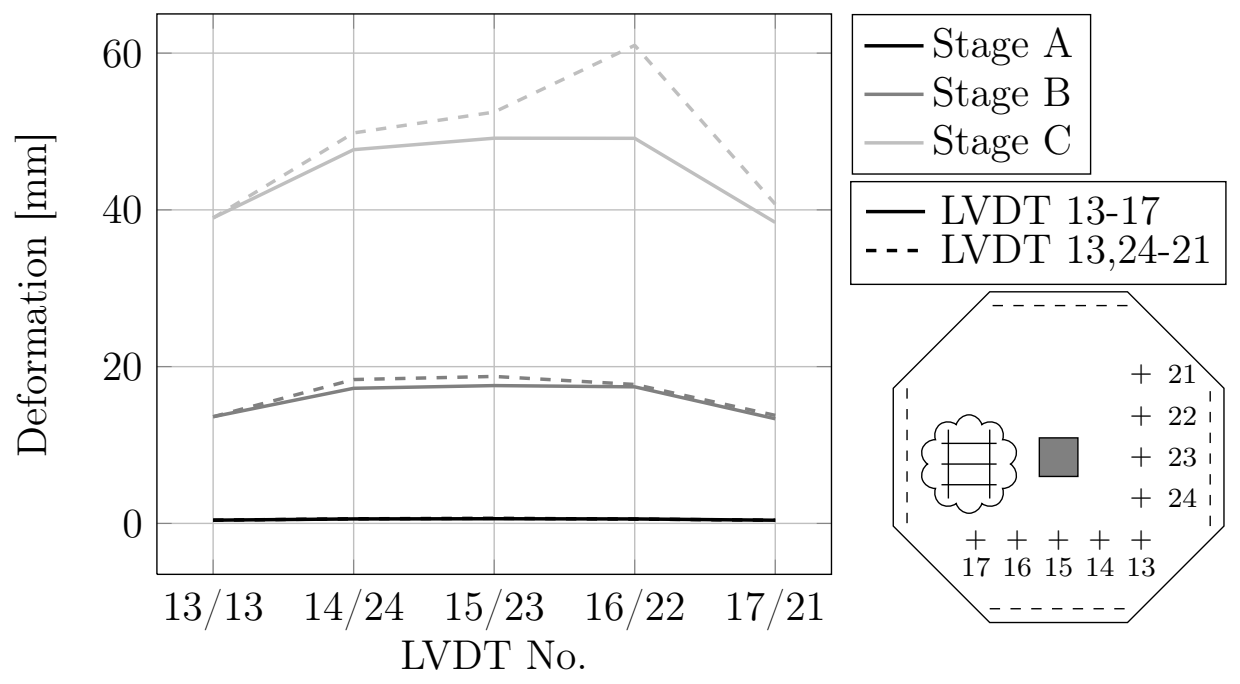

Figure 12: Deformation in intermediate positions, Slab CR3. Three stages of loading is shown (at mid point deflection of about 1, 30, and 100mm), in analogy with Figure 14 .
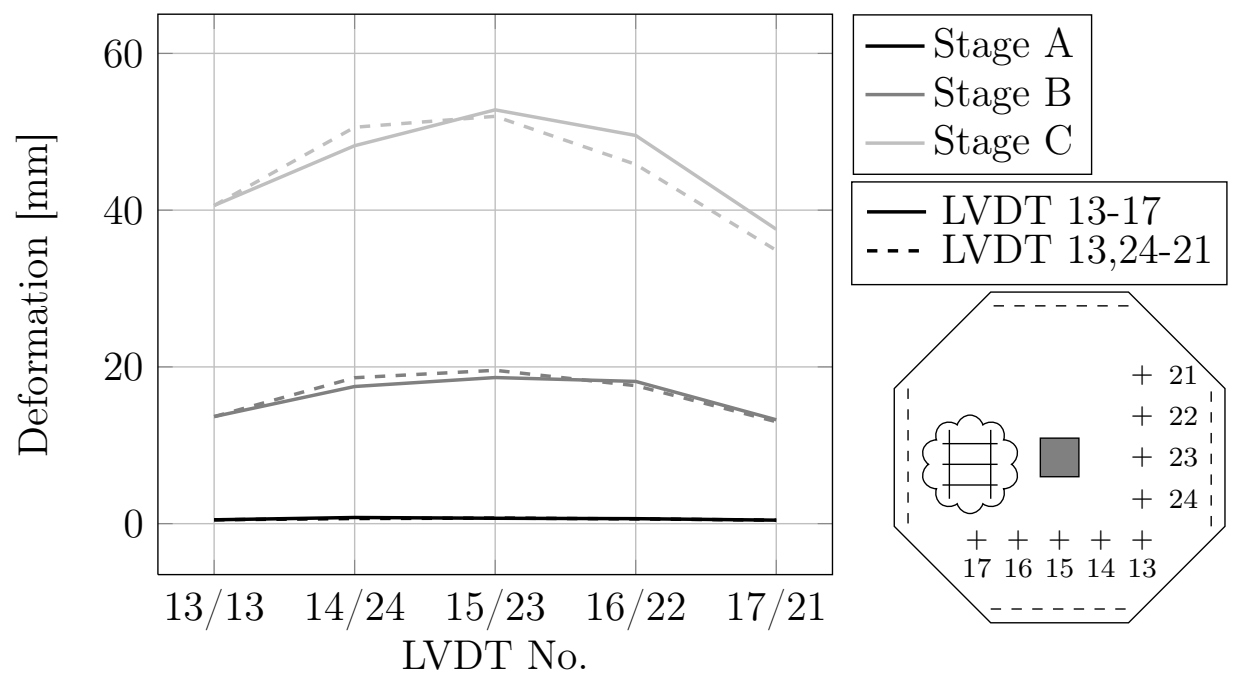

Figure 13: Deformation in intermediate positions, Slab CFR2. Three stages of loading is shown (at mid point deflection of about 1, 30, and 100mm), in analogy with Figure 15 .

\subsection{Crack patterns}

Figures 14 and 15 show sketches of the final crack patterns for the slab types with conventional reinforcement. Generally, initial cracks (appearing at the end of the elastic stage) 
ranged from the centre of the slab diagonally towards the unsupported edges. As the maximum load was approached these cracks were the widest. The number of cracks increased gradually until a slight stiffness reduction could be observed in the load deflection graph (at 50-80 mm, Figure 11). Thereafter, energy was predominately absorbed through plastic deformation (crack width increase). The crack patterns obtained testing slabs with conventional reinforcement (Types CR and CFR), were not completely symmetrical, agreeing with the asymmetrical conventional reinforcement: cracks perpendicular to the denser reinforcement did not propagate as far as the corresponding crack perpendicular to the weak direction. The crack pattern of slab FR1 is shown in Figure 16. Although only one slab of each reinforcement configuration is presented here, the remainder of the series showed similar behaviours. Considering the number of cracks obtained, an obvious difference emerged between the slabs with a hardening behaviour (including conventional reinforcement) and those with the ultimate capacity determined by the cracking load (steel fibres alone). In the latter, virtually no additional cracks were formed once the ultimate crack pattern had been formed; this occurred almost immediately following the first cracking. However, it was observed that the number of cracks was higher in the slab with both conventional and steel fibre reinforcement. Furthermore, the crack widths were considerably reduced by adding steel fibres compared to the slabs with conventional reinforcement alone. This agrees well with the previously known behaviour of steel fibre reinforced concrete; the number of cracks increases, but the crack width is generally smaller [30, 31, 32, 33]. 


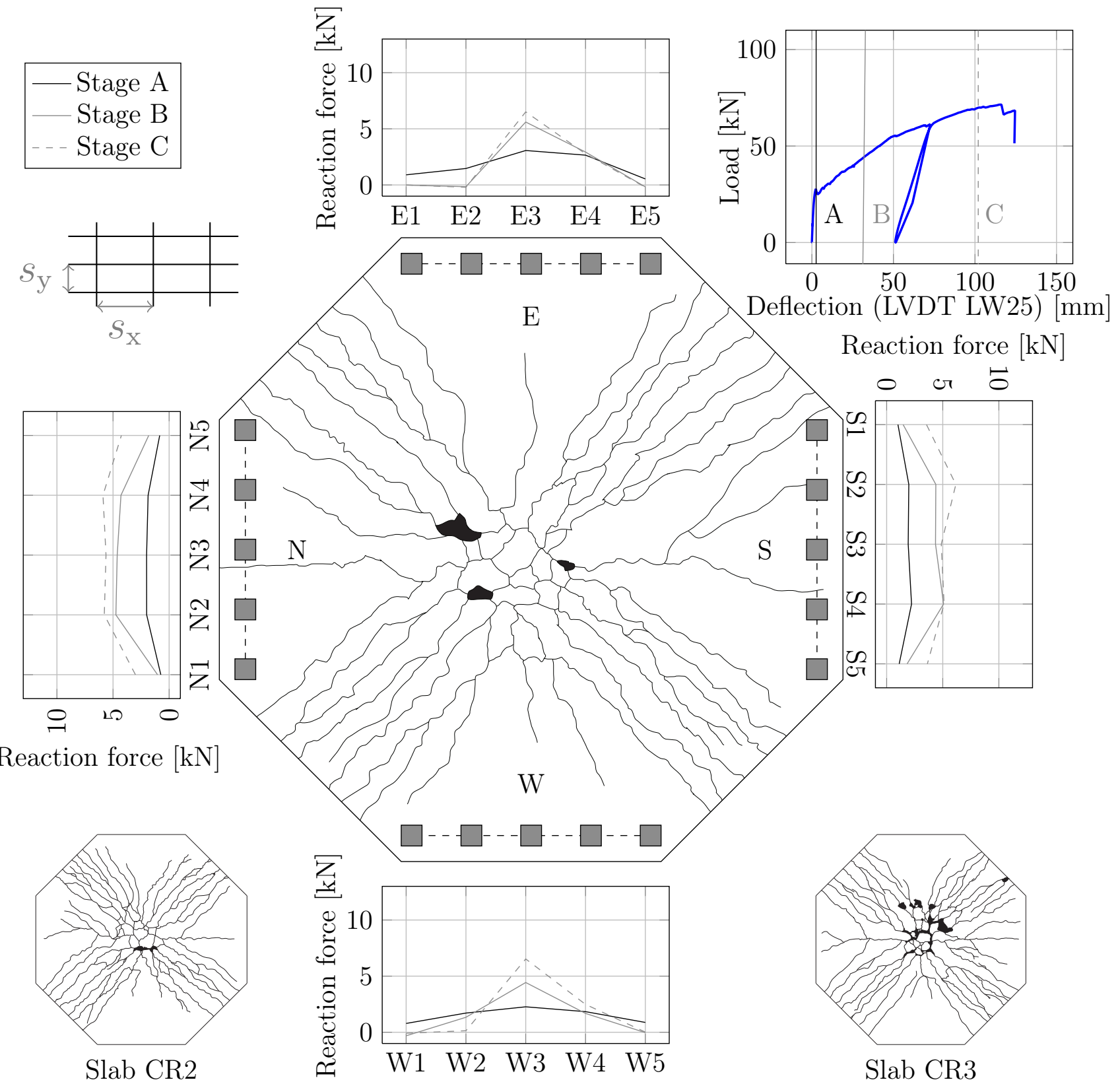

Figure 14: Crack patterns and reaction force distribution, Specimen CR1. The black areas represent spalled off areas. The reaction forces are given for three stages (A-C) as defined in the load versus displacement plot in the top right corner. 


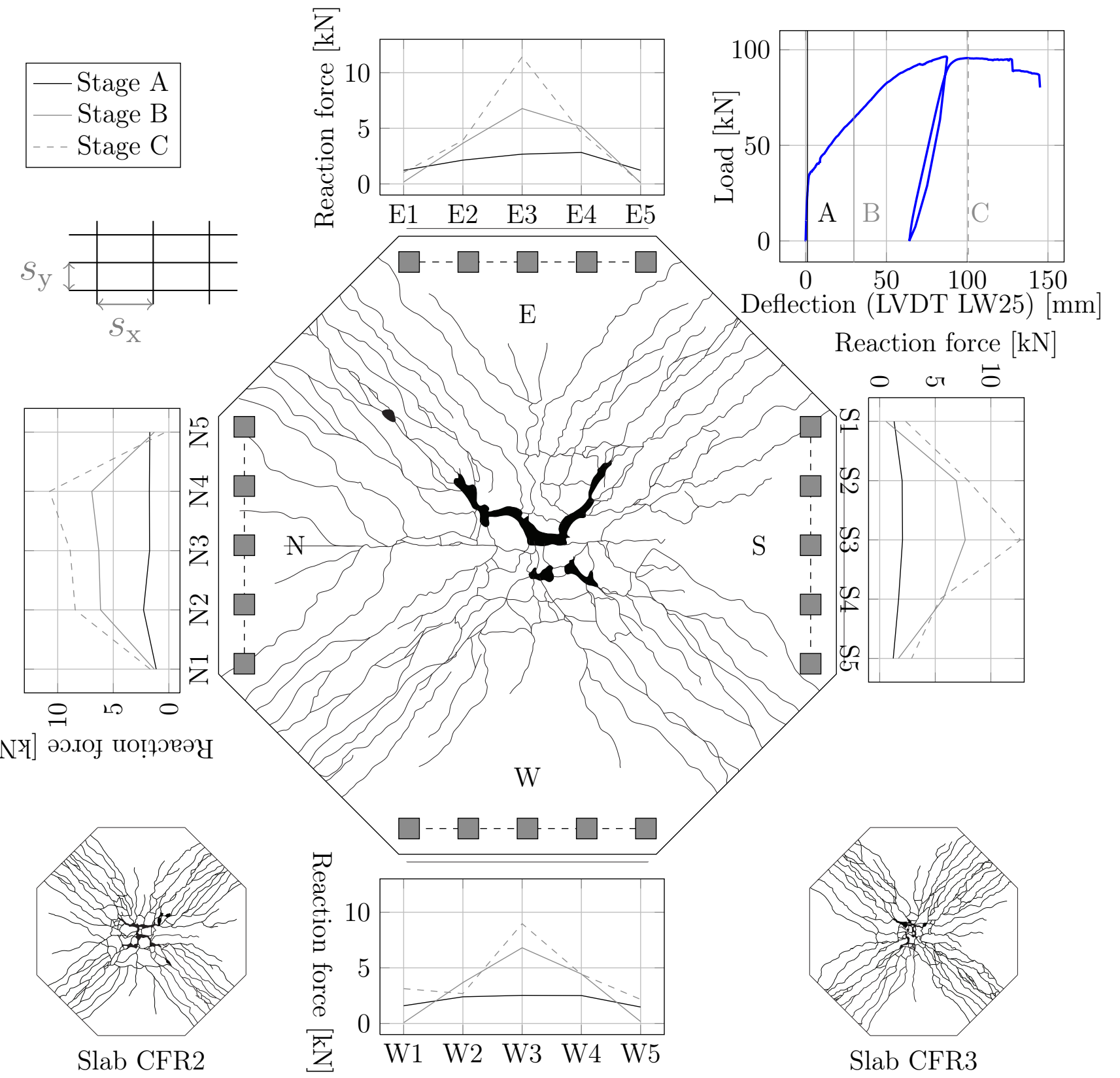

Figure 15: Crack patterns and reaction force distribution, Specimen CFR1. The black areas represent spalled off areas. The reaction forces are given for three stages (A-C) as defined in the load versus displacement plot in the top right corner. 


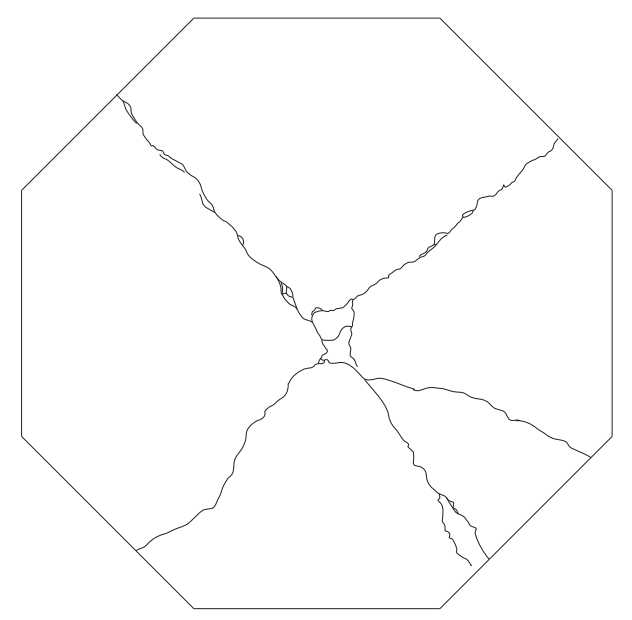

Figure 16: Crack pattern after testing slab with fibre reinforcement only (Specimen FR1).

\subsection{Reaction force distribution over the support length}

In Figures 14 and 15, the load distribution along the supported edges is visualised. It can be seen that for both CR and CFR slab types, the reaction forces over the supports were more equally distributed in the strong than in the weak direction. Thus, the denser reinforcement perpendicular to the support transferred to a higher extent the load transversely. The fibres caused a slightly more even distribution along the support lines in the weak direction, especially at large deflections (Stage $\mathrm{C}, \approx 100 \mathrm{~mm}$ ), where larger reaction forces were obtained in the outer rollers also in the weak direction. The reaction force prior to loading (i.e. the self-weight) has been deducted from all reaction forces presented.

\subsection{Reaction force versus deflection}

As previously described, the influence of steel fibres on the load redistribution was of interest to the present study. In Figure 17, the total reaction forces at the supports in the strong and weak directions are presented. For clarity, only results from two selected slabs are presented. Similar behaviour was, however, observed throughout the test series, as seen in Figure 18, where the support reactions in relation to the total load are presented for all slabs. The reaction force was also measured for the slab reinforced with steel fibre reinforcement alone; however, the lack of conventional reinforcement gave a completely symmetric structure in which no redistributions could occur. 


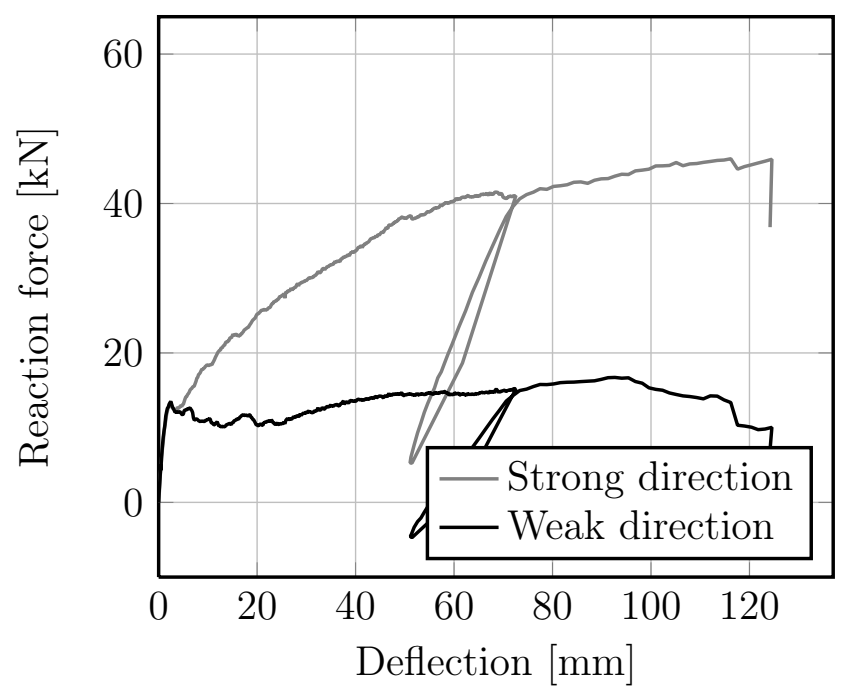

(a) CR1

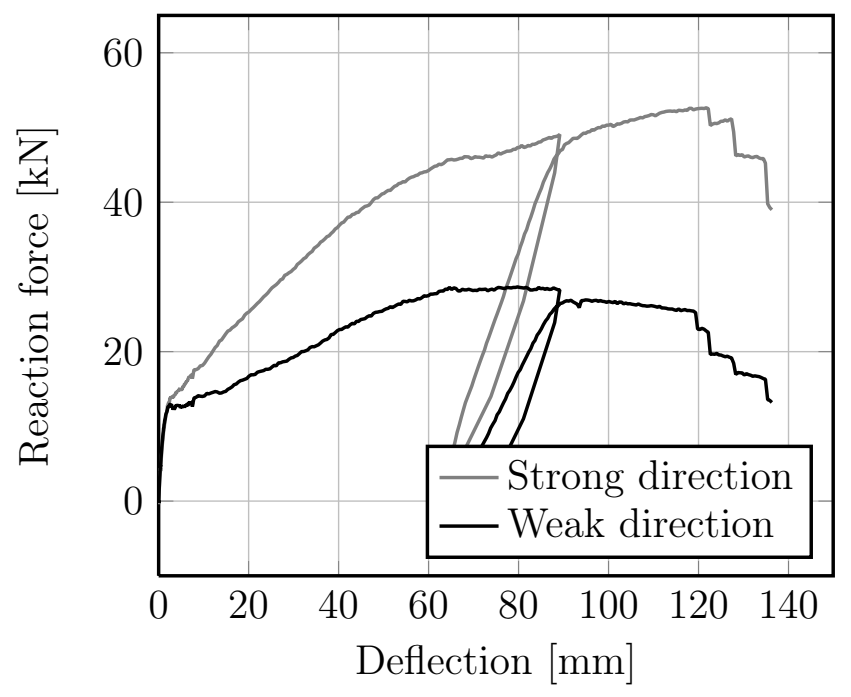

(b) CFR2

Figure 17: Total reaction force per supported edge.

\subsection{Validation of reaction force measurements}

The method developed to measure the reaction forces rely on the strains measured on the support rollers, in addition to the calibration of these strains to forces. To evaluate the accuracy of this method, the applied load was compared to the total reaction force evaluated (excluding the self-weight) in Figure 19. These forces must be equal to fulfil equilibrium and any deviation must be considered an error in monitoring technique. As seen, the overall agreement was rather satisfactory; however, an increasing deviation between the load applied and the reaction force evaluated could be observed with increasing 


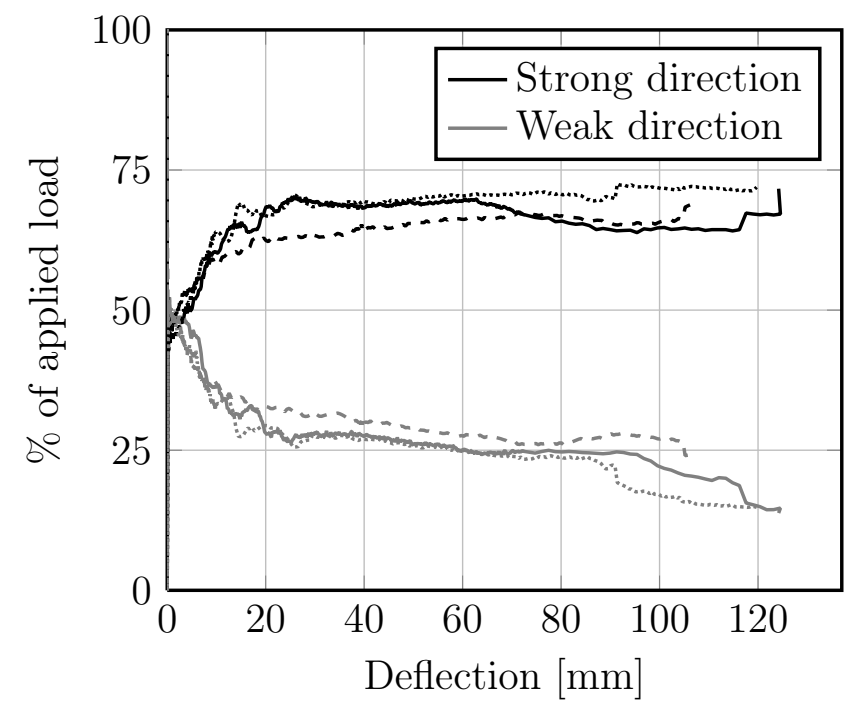

(a) Conventional reinforcement only (CR)

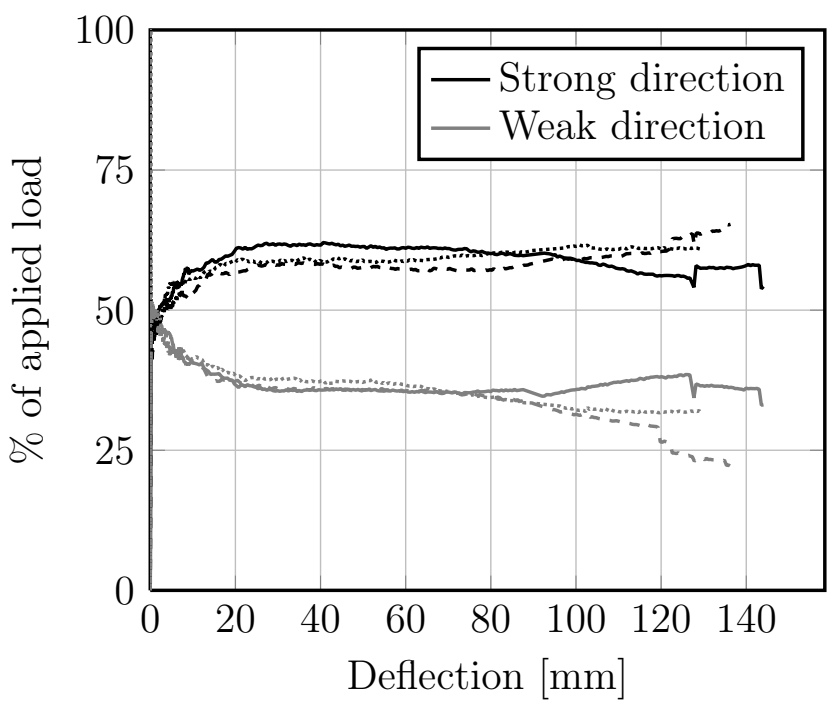

(b) Conventional and steel fibre reinforcement (CFR)

Figure 18: Ratio of load carried by the supports in the strong and weak direction for CR slabs (a) and CFR slabs (b). In both series, the line type denotes the specimen number (1-solid ,2-dashed, 3-dotted).

deformation. Parts of the error increase at the latter stages of loading can be attributed to the increasing rotation of the support rollers, as discussed in Section 2.4. It should be mentioned that the results shown are for the slabs with the largest deviation of this kind; for other slabs the trend towards increasing deviation for larger deformation was similar, but the magnitude was less. The error is considered acceptable. 

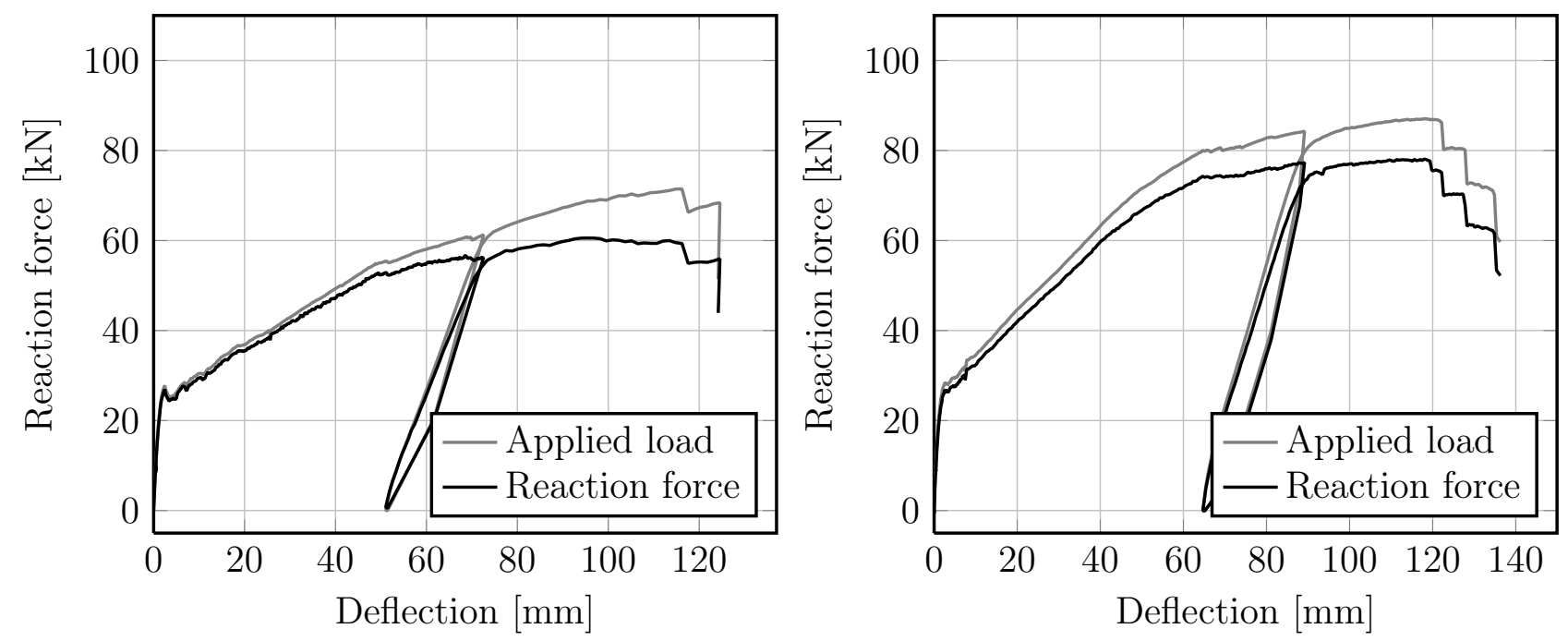

(a) CR1, max. difference: $12.7 \mathrm{kN}(18.6 \%)$ at $123.2 \mathrm{~mm}(\mathrm{~b}) \mathrm{CFR} 2$, max. difference: $12.2 \mathrm{kN}(15.3 \%)$ at 127.8 $\mathrm{mm}$

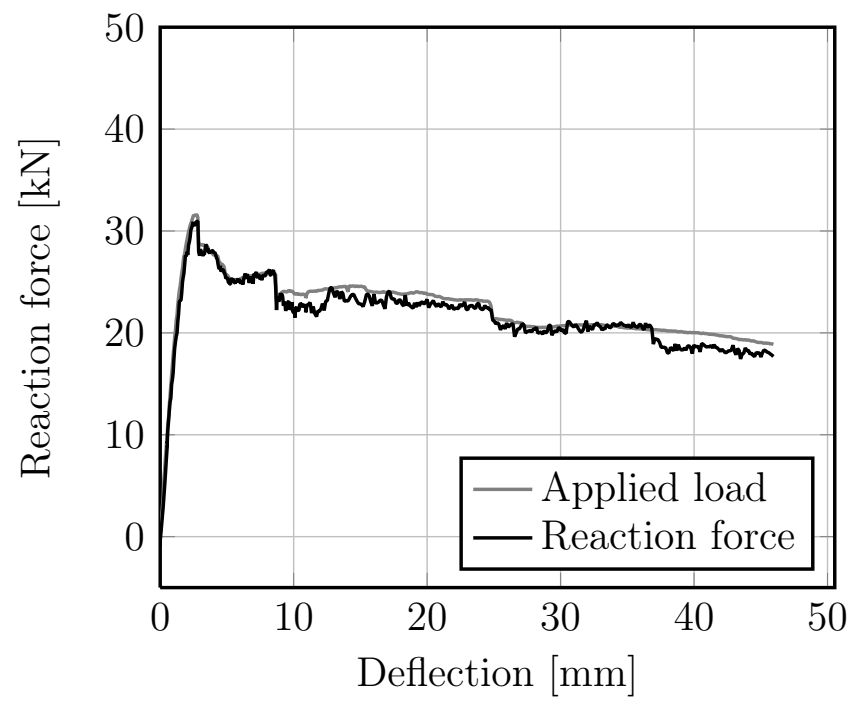

(c) FR2, max. difference: $2.4 \mathrm{kN}(10.3 \%)$ at $11.7 \mathrm{~mm}$

Figure 19: Comparison of applied load and measured reaction force.

\section{Discussion}

\subsection{Effects from steel fibre on the load distribution}

Considering the results presented Figure 17, a strong influence of steel fibres on the load distribution after cracking can be observed. In the CFR series, the load carried by the supports in the weak direction continued to increase after cracking, while almost no increase of the support reaction in the weak direction was observed in the CR series. Comparing 
the overall behaviour (Figure 11), it could be claimed that the main part of the additional load carrying capacity was added by providing better redistribution capacity through the addition of steel fibres. The load carried by the supports in the weak direction increased as much as about $60 \%$ by the presence of steel fibres. On the other hand, the load carried by the supports in the strong direction, only increased by about $13 \%$ by the presence of fibres. Also in absolute numbers, the increase in the weak direction is larger than in the strong, $25 \mathrm{kN}$ compared to $6 \mathrm{kN}$.

\subsection{Load distribution over the support length}

In Section 4.3, the load distributions along the support length are presented. To elaborate, the number of supporting rollers in compression at a midspan deflection of $100 \mathrm{~mm}$ is presented in Figure 20. As a result, a clear trend becomes evident; the difference between the strong and weak directions becomes more pronounced in the slabs with conventional reinforcement alone (CR). A concept used for describing the transversal load distribution is based on an effective width, describing the support width assumed to carry the applied load. Describing the findings of the present study in these terms, we found that the effective widths were considerably larger for the supports in the strong direction. When adding steel fibres, the pronounced difference seen in the slab with conventional reinforcement alone is evened out. In the CR slabs, all support rollers in the strong direction were utilised, while on an average only $56.7 \%$ of the support rollers in the weak direction support roller were in compression. The corresponding average utilisation for the CFR slabs were $90.0 \%$ and $73.3 \%$ in the strong vs. weak direction, respectively. As previously described, the initial cracks dominated the crack pattern in the slabs with steel fibre reinforcement alone. The direction of these cracks affected the load distribution; thus, our observations turned out to be inconclusive.

The distribution of load over the support length is taken in account designing for shear forces, and have recently been studied both experimentally and in numerical analysis [34]. It is interesting to note that the differences observed in the present study between the strong and weak directions are neither taken into account in EC2 [21] nor in Model Code 2010 [35, not even for conventional reinforcement alone. A more refined assessment of the actual behaviour, could lead to that a more generous support width could be utilized. Secondly, the smearing effect from steel fibres on the transversal distribution of load observed could be further quantified and taken into account in a more refined model.

\subsection{Comparison to yield line analysis using Model Code 2010}

The analytically estimated capacity of the slabs reinforced with conventional reinforcement alone, as described in Section 2.3 , was $40.5 \mathrm{kN}$. The average corresponding ultimate load obtained from experiments was $69.9 \mathrm{kN}$. This underestimation is mainly attributed to two effects: the lack of strain hardening in the yield line model and membrane effects. Using the yield line method, the reinforcement is considered ideal plastic; hence, the tension hardening observed for the reinforcement bars was neglected. The contrary approach would be to instead calculate the moment capacity using the ultimate strength of the reinforcement (666 MPa, as per Section 3.4). Using the same yield line solution, 


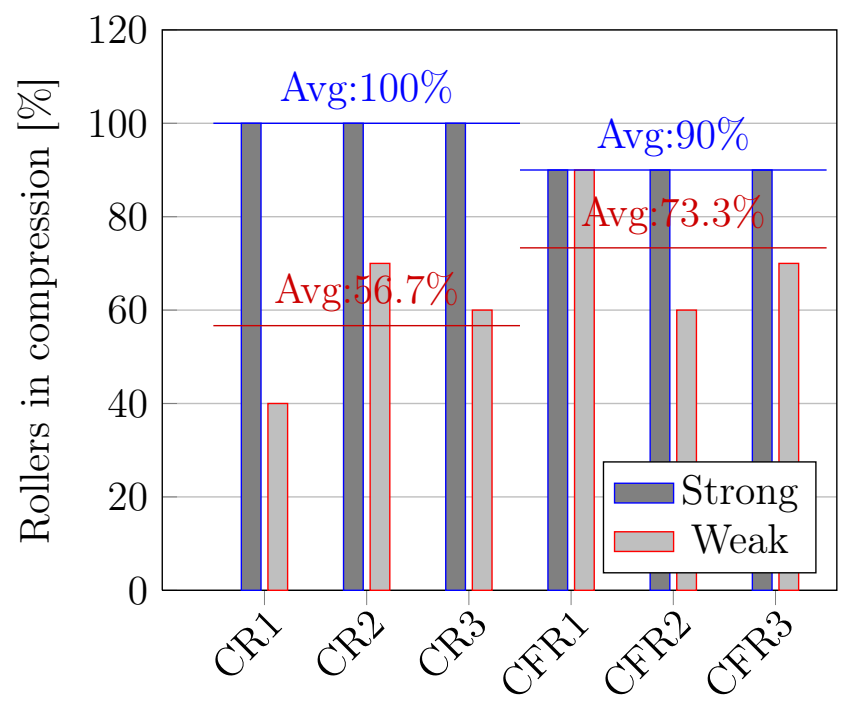

Figure 20: Number of rollers supporting the slabs in strong and weak direction, respectively, at a midspan deflection of $100 \mathrm{~mm}$.

this approach would increase the ultimate load estimated to $49.0 \mathrm{kN}$. Due to the multidirectional load carrying, membrane effects occur in slabs with no horizontal restraint as documented by Ockleston [36] and later described and quantified by several researchers [37, 38, 39, 40]. In brief, as tensile and compressive in-plane stresses arise the load capacity increases. Considering the deflection of a one-way slab, as the slab deforms, the edges move toward the centre. To prevent this movement, tensile stress is created in the slab. In a two-way slab, simply supported on four edges, the perpendicular load-carrying direction restrains the horizontal movement of the other direction, giving rise to in-plane forces as described for the one-way slab. Furthermore, tensile stresses will arise in the counteracting direction. Consequently, in a two-way slab, these stresses will occur in both directions, resulting in tensile in-plane forces in the centre of the slab surrounded by a ring of compressive forces. The yield moment will increase in the areas with compressive forces. The results from Bailey [38] indicate that the increasing factor for the ultimate load of a simply supported square slab with the displacement/effective depth-ratio of the slabs studied would be approximately 1.5. This result explains the major difference between the yield line analysis and the experimental capacity of the slabs reinforced with conventional reinforcement alone. It should be stressed that the factor suggested by Bailey [38] is valid only for isotropic reinforcement arrangement and for a square slab supported vertically only. On one hand, the slab corners were left out in the current study, thereby likely decreasing the membrane effect. On the other hand, the assumption of vertical support alone might be questioned. It is likely that the supporting pipes, through friction, would add a partial horizontal restraint in the direction along the pipes, thereby increasing the membrane effects. Quantification of these effects is not within the scope of this paper; however, it is considered to be of minor magnitude. 
To include the effect of steel fibre reinforcement in the analytical solution, the sectional moment resistance was calculated utilising a stress and strain distribution as suggested in Model Code 2010 (MC 2010). In MC 2010, three conditions are given for the ultimate sectional moment capacity; one of these three conditions is limiting. In practice, one of them, the attainment of the ultimate tensile strain of the conventional reinforcement is not relevant, in most cases, as it is mainly of concern when cold-drawn reinforcement bars are used. The remaining two conditions treat the attainment of the maximum tensile strain $\left(\varepsilon_{\mathrm{fu}}\right)$ or maximum compressive strain $\left(\varepsilon_{\mathrm{cu}}\right)$, respectively (Figure 21).

As formulated in MC 2010, it was not evident to the authors which criteria should be chosen in design: either the failure criteria obtained at the lowest curvature, or the criteria resulting in the lowest, or even possibly highest, ultimate load. Adopting the cross-sectional model resulting in the lowest curvature would provide the solution that physically occurs first; however, the cross-sectional model resulting in the lowest moment capacity (or load) would always reflect the most conservative option. In the current study, reaching the ultimate tensile strain in the most tensioned side of the cross-section is followed by continued loading until the ultimate compressive strain is attained. The tensile stress block was limited to the part where the tensile strain was not exceeding the ultimate tensile strain. The final stress distribution obtained with this interpretation of MC 2010 is exemplified in Figure 21b. The sectional moment capacities calculated for both ultimate cross-section assumptions are presented along with the curvature in Table 4.

Table 4: Sectional moment capacities and curvatures calculated applying the sectional models as presented in Figure 21.

\begin{tabular}{l|rr|rr} 
Failure assumption & $m_{\mathrm{x}}[\mathrm{kNm} / \mathrm{m}]$ & $m_{\mathrm{y}}[\mathrm{kNm} / \mathrm{m}]$ & $(1 / r)_{\mathrm{x}}[1 / \mathrm{m}]$ & $(1 / r)_{\mathrm{y}}[1 / \mathrm{m}]$ \\
\hline Tensile strain & 11.3 & 6.7 & 0.276 & 0.269 \\
Compressive strain & 9.2 & 4.1 & 0.66 & 1.332
\end{tabular}

The highest capacity is obtained as the ultimate tensile strain is reached. If this would not be considered as a failure criteria, after continued increase of curvature the ultimate compressive strain will be attained at a lower sectional resistance. As formulated in MC 2010, it was not evident which criteria should be chosen in design: either the failure criteria obtained at lowest curvature, or the criteria resulting in the lowest, or even possibly highest, ultimate load. The cross-sectional model resulting in the lowest curvature will physically occur first; however the cross-sectional model resulting in the lowest moment capacity (or load) would always provide the most conservative option. In this study, both cases were compared to the experimental load-carrying capacities.

Material properties were evaluated from the three point-bending tests (Table 3). In accordance with RILEM TC 162-TDF [4] the mean force recorded under loading, $F_{3}$, is calculated as 


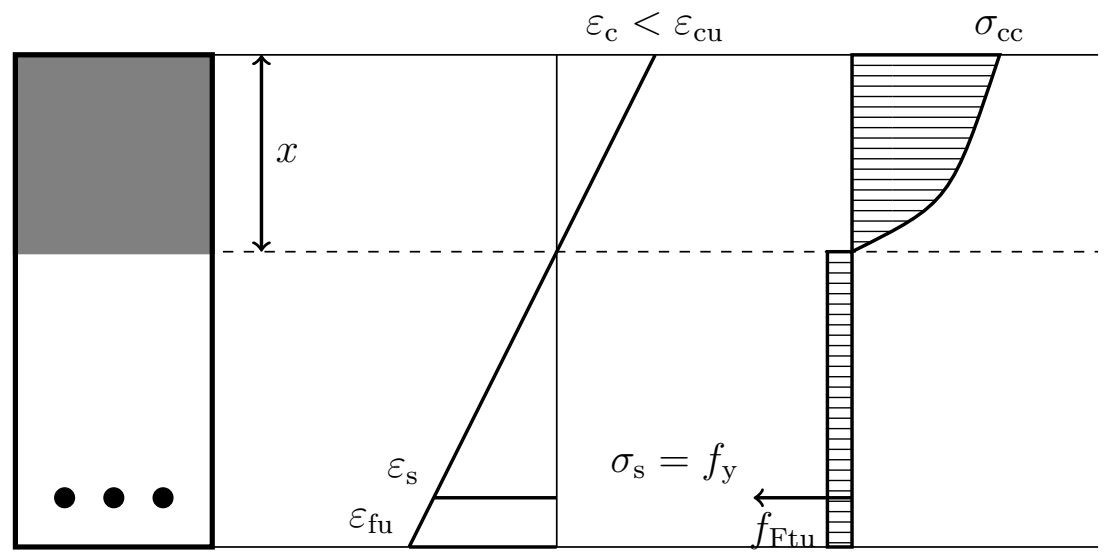

(a) Assuming tensile failure, by reaching the ultimate tensile strain on the tensioned side of the beam.

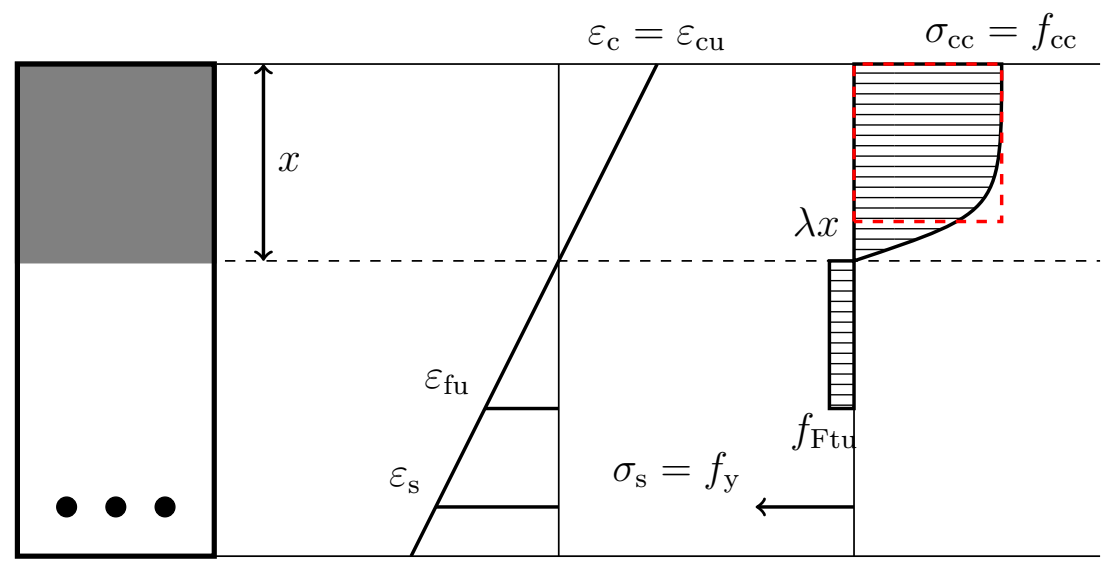

(b) Assuming compressive failure.

Figure 21: Sectional models used for fibre reinforced concrete.

$$
F_{3}=\frac{D_{\mathrm{BZ} 3}}{2.5 \mathrm{~mm}}
$$

The residual flexural strength corresponding to the crack mouth opening displacement $\mathrm{CMOD}_{3}=2.5 \mathrm{~mm}, f_{\mathrm{R} 3}$, could then be calculated as

$$
f_{\mathrm{R} 3}=\frac{3 F_{3} l_{\mathrm{z}}}{2 b_{3 \mathrm{PBT}} h_{\mathrm{sp}}^{2}} .
$$

Using the average value of the residual strength above, and assuming a plastic stress distribution in the tensioned steel fibre reinforced concrete, the reference value could then be calculated in accordance with MC 2010 [35], 


$$
f_{\mathrm{Ftu}}=\frac{f_{\mathrm{R} 3}}{3}=0.915 \mathrm{MPa} .
$$

The corresponding ultimate tensile strain was conservatively chosen to $\varepsilon_{\mathrm{fu}}=2 \%$. Considerably higher capacities were obtained adopting the attainment of the ultimate tensile strain as the governing failure criteria instead of assuming a compressive failure. Using the yield line method, as presented in Section 2.3, the ultimate load carrying capacities obtained were $55.5 \mathrm{kN}$ and $41.1 \mathrm{kN}$, for the both sectional models, respectively. To obtain a fully comparable value for plain concrete, the sectional moment resistance was calculated using a simplified compressive stress distribution. This sectional moment capacity yielded an ultimate load of $39.4 \mathrm{kN}$; hence the estimated contribution of the steel fibres to the ultimate load carrying capacity was about $4 \%$ or $40 \%$ depending on the assumption made for the cross-section. It should be mentioned that the concrete properties were slightly different, comparing plain and fibre reinforced concrete (Table 2). As previously discussed, strain hardening of the conventional reinforcement was not included in the calculation. The analytical solutions are compared to the experimentally obtained ultimate loads in Figure 22, where the consistent underestimation of the different yield line solutions is evident.

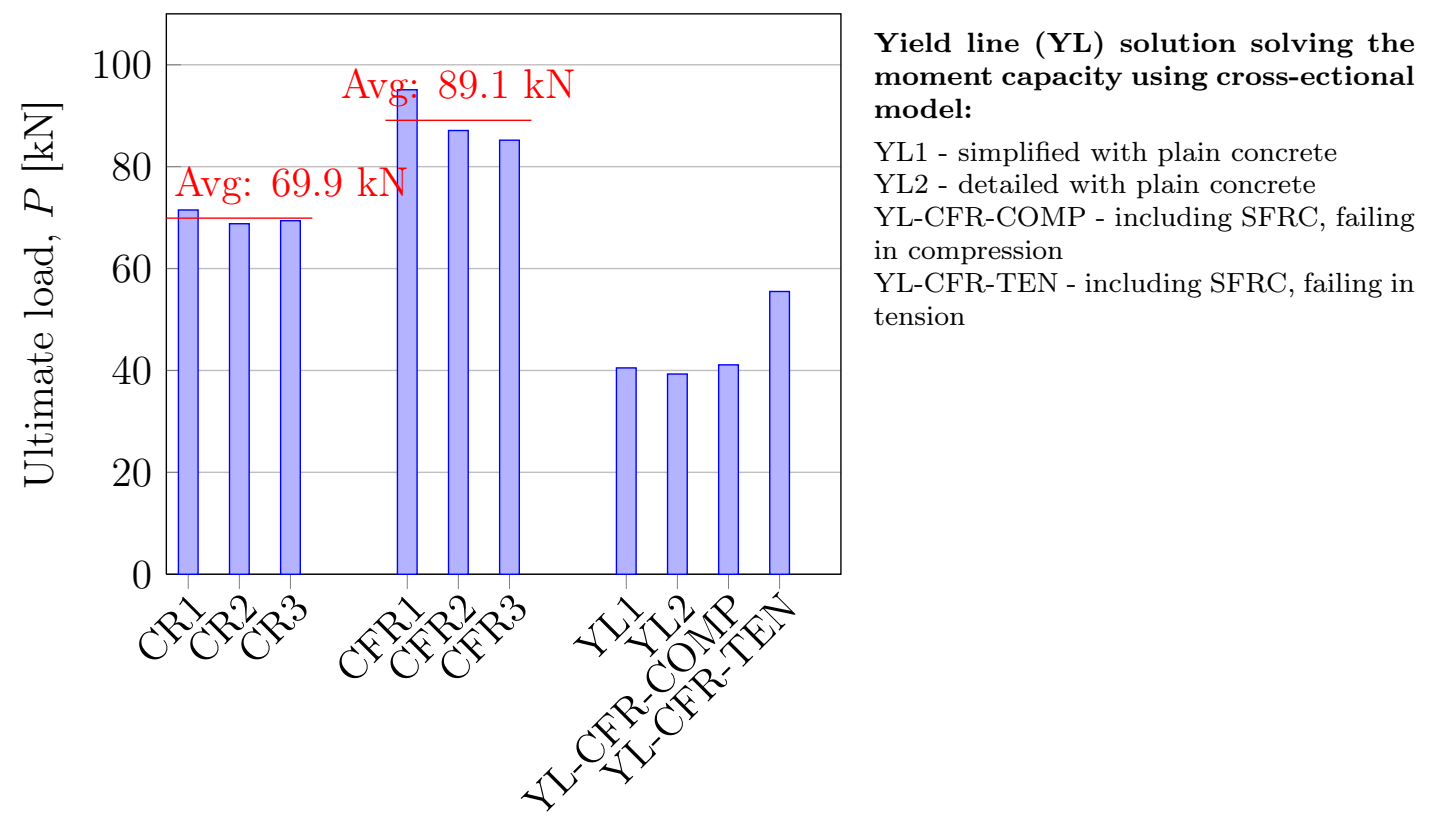

Figure 22: Comparison of experimentally and analytically obtained ultimate loads.

\section{Conclusions}

By monitoring the reaction forces in a statically indeterminate and asymmetrically reinforced slab, it was found that the addition of steel fibres reinforcement increased the 
proportion of load carried in the weak direction. No additional load was transferred to the supports in the weak direction after cracking, in slabs reinforced with conventional reinforcement alone. In steel fibre reinforced slabs the reaction forces of the supports in the weak direction were increased further, considerably enhancing the load-carrying behaviour. Generally, it could be concluded that the redistribution capacity of slabs with a combination of conventional reinforcement and steel fibres is at least as high as for structures with conventional reinforcement only. Practically, this indicates that design methods relying on load redistribution safely could be used also for combined reinforcement alternatives; although, further research should be carried out.

Using yield line theory, the ultimate load was largely underestimated because of membrane forces and strain hardening of the conventional reinforcement. Analytical estimations of the contribution from steel fibre reinforcement to the ultimate load carrying capacity, calculated as proposed in Model Code 2010 [35, were either heavily underestimated or rather accurate, depending on how the proposed sectional models were interpreted. This could be further clarified in future code suggestions.

Furthermore, this study showed that the difference seen in the effective support length diminished by the addition of steel fibres. Considering the slabs with conventional reinforcement alone, the full width of the support was utilised in the strong direction, while the support width in the weak direction was only partially utilised. In slabs with conventional and steel fibre reinforcement neither direction was fully utilized; however, the difference between the utilised lengths was reduced.

It was concluded that the steel fibres provided a significant addition in terms of load carrying capacity. Furthermore, the crack pattern behaved as expected: with steel fibre reinforced concrete combined with conventional reinforcement, additional cracks developed, but with narrower crack width compared to the slabs reinforced with conventional reinforcement alone.

The slabs reinforced with fibres alone did not experience bending hardening. It is interesting to note that the post-cracking capacity of these slabs, entirely depending on the fibres in the concrete, roughly corresponds to the addition in ultimate load capacity provided by the fibres when combined with conventional reinforcement. It might be argued that this is a coincidence, valid only for this specific geometry and material. However, with further research, a simplified model to estimate the beneficial effect of steel fibres, valid for a limited range of standard elements, might be established.

The method developed to monitor the reaction forces by using strain gauges on steel pipes was successful, and the instrumentation in terms of displacement measurements (LVDTs) was sufficient. Parameters to be varied in future studies would include the ratio of conventional reinforcement in each direction (making the weak direction stronger) and the steel fibre content. 


\section{Acknowledgement}

This research was funded by the Seventh Framework Programme of the European Community under grant agreement NMP2-LA-2009-228663 (TailorCrete). More information on the TailorCrete project can be found at www.tailorcrete.com.

\section{Notations}

$\begin{array}{ll}(1 / r)_{i} & \text { Curvature of cross-section in direction } i \\ \alpha & \text { Angle at which the reinforcement intersects the yield line } \\ \alpha & \text { Rotation angle of support roller } \\ \delta & \text { Virtual displacement by the point load } P \\ \delta_{i} & \text { Deflection corresponding to CMOD } i \\ \delta_{\mathrm{L}} & \text { Deflection at the limit of proportionality in three-point bending test } \\ \epsilon_{\mathrm{c}} & \text { Concrete strain } \\ \epsilon_{\mathrm{cu}} & \text { Ultimate compressive strain } \\ \epsilon_{\mathrm{fu}} & \text { Ultimate tensile strain } \\ \epsilon_{\mathrm{s}} & \text { Strain in reinforcement bar } \\ \lambda & \text { Factor taking the non-linear distribution of compressive stresses into account } \\ \sigma_{\mathrm{s}} & \text { Stress in reinforcement bars } \\ \sigma_{\mathrm{cc}} & \text { Compression stress in concrete } \\ \theta & \text { Rotation angle in the yield lines } \\ \phi & \text { Reinforcement diameter } \\ A_{\mathrm{s} i} & \text { Reinforcement area in direction } i \\ \mathrm{CMOD} & \text { Crack mouth opening displacement } i \\ D_{\mathrm{BZ} i} & \text { Energy absorption capacity, corresponding to CMOD } i \\ E_{c} & \text { Elastic modulus of concrete } \\ E W & \text { External work on the slab } \\ F_{i} & \text { Load in three-point bending test, corresponding to CMOD } i \\ F_{\mathrm{L}} & \text { Load at the limit of proportionality in three-point bending test } \\ L_{\mathrm{S}} & \text { Half diagonal of a square slab (Figure } 2 \\ L_{\mathrm{Y}} & \text { Length of a yield line } \\ I W & \text { Internal work resisted by the reinforcement in the slab } \\ P & \text { Point load } \\ V_{\mathrm{f}} & \text { Fibre content in percentage } \\ b_{3 \mathrm{PBT}} & \text { Width of three-point bending specimen } \\ d & \text { Diameter (of specimen) } \\ d_{i} & \text { Internal lever arm of reinforcement in direction } i \\ f_{\mathrm{y}} & \text { Yield strength of reinforcement } \\ f_{\mathrm{c}, \text { mean }} & \text { Mean compressive strength of concrete }\end{array}$




$\begin{array}{ll}f_{\mathrm{ct}, \mathrm{mean}} & \text { Mean tensile strength of concrete } \\ f_{\mathrm{Ftu}} & \text { Reference value describing the residual strength in cross-sectional analysis } \\ f_{\mathrm{R} i} & \text { Residual flexural strength, corresponding to CMOD } i \\ h & \text { Height (of specimen) } \\ h_{\mathrm{sp}} & \text { Notched height of three-point bending specimen } \\ l_{\mathrm{z}} & \text { Span length in three-point bending test } \\ m_{\mathrm{b}} & \text { Moment resisted by reinforcement } \\ m_{i} & \text { Moment capacity of the reinforcement in direction } i \\ s_{i} & \text { Spacing between reinforcement bars in direction } i \\ t & \text { Thickness } \\ x & \text { Height of the compressive zone }\end{array}$

\section{References}

\section{References}

[1] Stang H, Aarre T. Evaluation of crack width in FRC with conventional reinforcement. Cement Concrete Comp 1992;14(2):143 -54.

[2] Barros J, Figueiras J. Flexural behavior of SFRC: Testing and modeling. J Mater Civil Eng 1999;11(4):331-9.

[3] Vandewalle L. Cracking behaviour of concrete beams reinforced with a combination of ordinary reinforcement and steel fibers. Mater Struct 2000;33(227):164-70.

[4] RILEM TC 162-TDF . Bending test. Mater Struct 2002;35(9):579-82.

[5] RILEM TC 162-TDF . Uni-axial tension test for steel fibre reinforced concrete. Mater Struct $2001 ; 34(1): 3-6$.

[6] Sorelli L, Meda A, Plizzari G. Steel fiber concrete slabs on ground: A structural matter. ACI Struct J 2006;103(4):551-8.

[7] Alani A, Beckett D, Khosrowshahi F. Mechanical behaviour of a steel fibre reinforced concrete ground slab. Mag Concrete Res 2012;64(7):593-604.

[8] Døssland ÅL. Fibre reinforcement in load carrying concrete structures : Laboratory and field investigations compared with theory and finite element analysis. Ph.D. thesis; Norwegian University of Science and Technology, Department of Structural Engineering; 2008.

[9] Pujadas P, Blanco A, Fuente A, Aguado A. Cracking behavior of FRC slabs with traditional reinforcement. Mater Struct 2012;45(5):707-25.

[10] Michels J, Waldmann D, Maas S, Zürbes A. Steel fibers as only reinforcement for flat slab construction - experimental investigation and design. Constr Build Mater $2012 ; 26(1): 145-55$. 
[11] Nguyen-Minh L, Rovnak M, Tran-Ngoc T, Le-Phuoc T. Punching shear resistance of post-tensioned steel fiber reinforced concrete flat plates. Engineering Structures 2012;45:324-37.

[12] Hillerborg A. Strip method design handbook. London: E \& FN Spon; 1996.

[13] Johansen KW. Yield-line formulae for slabs. London: Cement and Concrete Association; 1972. ISBN 0-7210-0819-4.

[14] di Prisco M, Plizzari G, Vandewalle L. Fibre reinforced concrete: new design perspectives. Mater Struct 2009;42(9):1261-81.

[15] McHarg P, Cook W, Mitchell D, Yoon YS. Benefits of concentrated slab reinforcement and steel fibers on performance of slab-column connections. ACI Struct J 2000;97(2):225-34.

[16] Yang JM, Yoon YS, Cook W, Mitchell D. Punching shear behavior of two-way slabs reinforced with high-strength steel. ACI Struct J 2010;107(4):468-75.

[17] Ganesan N, Indira P, Rajendra Prasad S. Structural behaviour of steel fibre reinforced concrete wall panels in two-way in-plane action. Indian Concrete J 2010;84(10):21-8.

[18] Doh J. Experimental and theoretical studies of normal and high strength concrete wall panels. Phd thesis; Griffith University; Gold Coast Campus, Australia; 2002.

[19] Blanco A. Characterization and modelling of sfrc elements. Ph.D. thesis; Universitat Politecnica de Catalunya; 2013.

[20] Pujadas P, Blanco A, Cavalaro S, Aguado A. Plastic fibres as the only reinforcement for flat suspended slabs: Experimental investigation and numerical simulation. Constr Build Mater 2014;57(0):92 - 104.

[21] EN 1992-1-1: Eurocode 2: Design of concrete structures - part 1-1: General rules and rules for buildings. Comité Européen de Normalisation (CEN); 2004.

[22] Wight JK, Macgregor JG. Reinforced Concrete: Mechanics and Design; chap. 14. Upper Saddle River, NJ: Pearson Education Inc.; 6 ed. ISBN 978-0-13-217652-1; 2012 .

[23] Williams Portal N. Sustainability and flexural behaviour of textile reinforced concrete. Licenciate thesis; Department of Civil and Environmental Engineering, Chalmers University of Technology, Gothenburg, Sweden; 2013.

[24] Michels J, Christen R, Waldmann D. Experimental and numerical investigation on postcracking behavior of steel fiber reinforced concrete. Eng Frac Mech 2013;98(0):326 -49 . 
[25] Svec O. Flow modelling of steel fibre reinforced self-compacting concrete. Phd thesis; Technical University of Denmark, Department of Civil Engineering; Copenhagen, Denmark; 2013.

[26] Laranjeira F, Aguado A, Molins C, Grunewald S, Walraven J, Cavalaro S. Framework to predict the orientation of fibers in frc: A novel philosophy. Cement Concr Res 2012;42(6):752-68.

[27] EN 12504-1: Testing concrete in structures - part 1: Cored specimens - taking, examining and testing in compression. Comité Européen de Normalisation (CEN); 2009.

[28] EN 12390-3: Testing hardened concrete - part 3: Compressive strength of test specimens. Comité Européen de Normalisation (CEN); 2009.

[29] Rempling R, Fall D, Lundgren K. Three point bending and uni-axial tension tests of double hook-end fibers. In: Kohouykova A, editor. 7th International Conference: Fibre Concrete 2013. Prague, the Czech Republic. ISBN 978-80-01-05239-6; 2013,.

[30] Bischoff PH. Tension stiffening and cracking of steel fiber-reinforced concrete. J Mater Civil Eng 2003;15(2):174-82.

[31] Vasanelli E, Micelli F, Aiello MA, Plizzari G. Long term behavior of FRC flexural beams under sustained load. Engineering Structures 2013;56(0):1858 -67.

[32] Abas F, Gilbert R, Foster S, Bradford M. Strength and serviceability of continuous composite slabs with deep trapezoidal steel decking and steel fibre reinforced concrete. Engineering Structures 2013;49:866-75.

[33] Fall D. Reinforcement in tailor-made concrete structures. Licenciate thesis; Department of Civil and Environmental Engineering, Chalmers University of Technology, Gothenburg, Sweden; 2011.

[34] Belletti B, Damoni C, Hendriks MA, de Boer A. Analytical and numerical evaluation of the design shear resistance of reinforced concrete slabs. Struct Conc 2014;.

[35] International Federation for Structural Concrete (fib) . fib Model Code for Concrete Structures. Wilhelm Ernst \& Sohn; 2010. ISBN 978-3-433-03061-5.

[36] Ockleston A. Load tests on a three storey reinforced concrete building in johannesburg. TheStructuralEngineer 1955;33(10):304-22.

[37] Sawczuk A, Winnicki L. Plastic behavior of simply supported reinforced concrete plates at moderately large deflections. Int J Solids Struct 1965;1(1):97 - 110.

[38] Bailey CG. Membrane action of unrestrained lightly reinforced concrete slabs at large displacements. Engineering Structures 2001;23(5):470 -83. 
[39] Foster S, Bailey C, Burgess I, Plank R. Experimental behaviour of concrete floor slabs at large displacements. Engineering Structures 2004;26(9):1231 -47.

[40] Nielsen M, Hoang L. Limit Analysis and Concrete Plasticity; chap. 6.11. Boca Raton, Florida: CRC Press LLC; 3 ed.; 2011, p. 560-77. 